IAB-DISCUSSION PAPER

\title{
13|2020 Evidence on Job Search Models from a Survey of Unemployed Workers in Germany
}

Stefano DellaVigna, Jörg Heining, Johannes F. Schmieder, Simon Trenkle Aktualisierte Version vom 18. Oktober 2021. / Updated Version as of 18 October 2021. 


\section{Evidence on Job Search Models from a Survey of Unemployed Workers in Germany}

Stefano DellaVigna (University of California at Berkeley, National Bureau of Economic Research (NBER)), Jörg Heining (Institut fuer Arbeitsmarkt- und Berufsforschung (IAB)), Johannes Schmieder (Boston University, NBER, IZA Institute for Labor Economics (IZA), CESIfo), Simon Trenkle (IZA, IAB)

Aktualisierte Version vom 18. Oktober 2021. / Updated Version as of 18 October 2021.

Mit der Reihe „IAB-Discussion Paper“ will das Forschungsinstitut der Bundesagentur für Arbeit den Dialog mit der externen Wissenschaft intensivieren. Durch die rasche Verbreitung von Forschungsergebnissen über das Internet soll noch vor Drucklegung Kritik angeregt und Qualität gesichert werden.

The "IAB-Discussion Paper" is published by the research institute of the German Federal Employment Agency in order to intensify the dialogue with the scientific community. The prompt publication of the latest research results via the internet intends to stimulate criticism and to ensure research quality at an early stage before printing. 


\section{Contents}

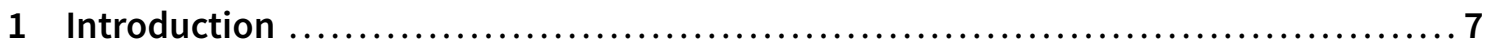

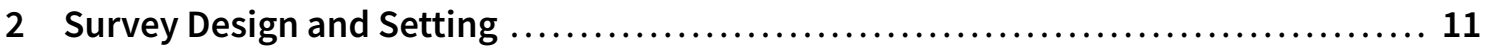

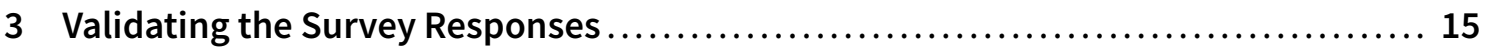

3.1 Basic Patterns of Search Effort Responses ................................ 15

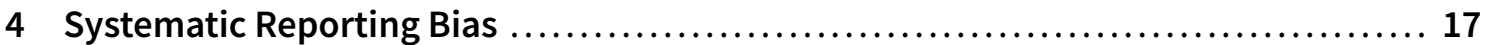

5 Job Search over the Unemployment Spell ................................... 18

5.1 Job search at the beginning of the unemployment spell ......................19

5.2 Job search around UI exhaustion .......................................20

5.3 Robustness....................................................... 20

5.4 Do job seekers time the start date of a job with the exhaustion of benefits? ......23

6 Reconciling the Survey Results with Job Search Models ........................ 24

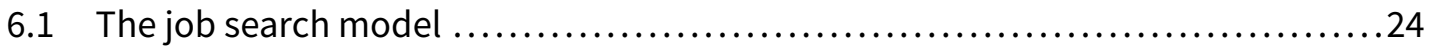

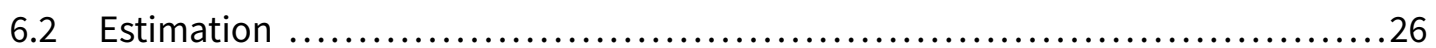

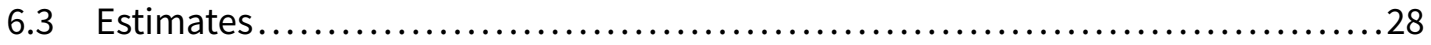

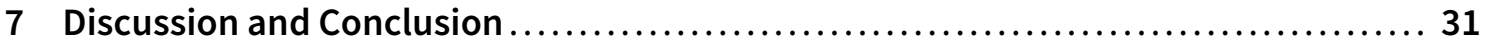

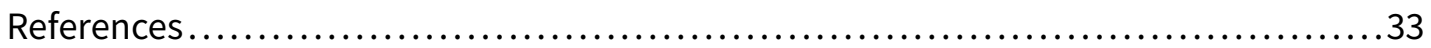

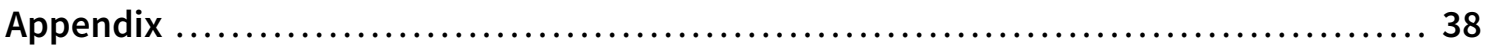

List of Figures

Figure 1: Re-employment Hazard Using Administrative Data ......................... 39

Figure 2: Survey Design ......................................................... 40

Figure 3: Distribution and Time Series of Job Search Measure ........................41

Figure 4: Validation of Search Effort Measure ....................................42

Figure 5: Search Effort (Minutes of Job-Search Yesterday) over the Unemployment Spell

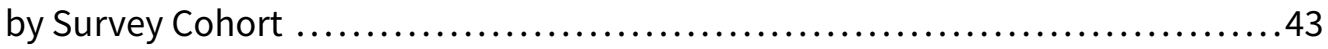

Figure 6: Search Effort Throughout the Unemployment Spell ........................ 44

Figure 7: Evidence about Storable Offer Model .................................. 45

Figure 8: Empirical Moments and Fit for Standard Model, Reference-Dependent Model, and Duration-Dependence Model ....................................46 


\section{List of Tables}

Table 1: Summary Table ..................................................48

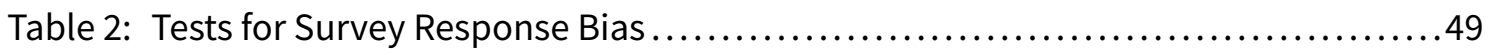

Table 3: Search Effort Since Start of UI Spell .................................... 50

Table 4: Search Effort Around UI Exhaustion ....................................... 51

Table 5: Robustness: Search Effort Around UI Exhaustion ............................. 52

Table 6: Structural Estimates of Job Search Models................................53 


\section{Abstract}

The job finding rate of Unemployment Insurance (UI) recipients declines in the initial months of unemployment and then exhibits a spike at the benefit exhaustion point. A range of theoretical explanations have been proposed, but those are hard to disentangle using data on job finding alone. To better understand the underlying mechanisms, we conducted a large text-message-based survey of unemployed workers in Germany. We surveyed 6,349 UI recipients twice a week for 4 months about their job search effort. The panel structure allows us to observe how search effort evolves within individuals over the unemployment spell. We provide three key facts: 1) search effort is flat early on in the UI spell, 2) search effort exhibits an increase up to UI exhaustion and a decrease thereafter, 3) UI recipients do not appear to time job start dates to coincide with the UI exhaustion point. A standard search model with unobserved heterogeneity struggles to explain the second fact, and a model of storable offers is not consistent with the third fact. The patterns are well captured by a model of referencedependent job search or by a model with duration dependence in search cost.

Updated Version as of 18 October 2021.

\section{Zusammenfassung}

Die Wahrscheinlichkeit eine neue Beschäftigung zu finden nimmt für Bezieher von Leistungen aus der Arbeitslosenversicherung in den ersten Monaten der Arbeitslosigkeit zunächst ab, steigt dann aber zum Ende der Bezugsdauer wieder an, um danach erneut abzuflachen. Zahlreiche theoretische Ansätze wurden bisher vorgeschlagen um dieses Muster zu erklären, jedoch ist dies kaum möglich sofern dafür nur Daten über die Tatsache der Arbeitsaufnahme an sich herangezogen werden. Um die zugrundeliegenden Mechanismen besser zu verstehen habe wir mittels SMS-Kurznachrichten eine groß angelegte Befragung von Arbeitslosen durchgeführt. Insgesamt wurden über 6.300 Leistungsbezieher zweimal pro Woche über jeweils vier Monate über der zeitlichen Aufwand bei der Suche nach einem neuen Arbeitsplatz befragt. Aufgrund der resultierenden Panelstruktur war es uns nun möglich Erkenntnisse zu sammeln, wie sich dieser zeitliche Aufwand auf individueller Ebene über die Dauer der Arbeitslosigkeit hinweg entwickelt. Unsere drei Hauptergebnisse lauten: 1) Der Suchaufwand verläuft flach zu Beginn der Arbeitslosigkeit. 2) Weiter steigt der Suchaufwand zum Ende der Bezugsdauer an, nimmt im Anschluss daran jedoch wieder ab. 3) Es gibt keine Anzeichen dafür, dass Leistungsbezieher die Aufnahme einer neuen Beschigung bewusst an das Ende der Bezugsdauer verzögern. Insbesondere das zweite und das dritte dieser Ergebnisse lassen sich kaum mit den Standardmodellen zur Arbeitssuche basierend auf unbeobachteter Heterogenität bzw. so genannten Storable Offer Modellen erklären. Dagegen können die genannten 
Ergebnisse gut mittels eines Suchmodells mit Reference Dependence erklärt werden.

Aktualisierte Version vom 18. October 2021.

JEL

J64, J65, D91

Keywords

Job search, Reference dependence, Survey, Unemployment

\section{Acknowledgements}

We would like to thank the Institute for Employment Research (IAB) for funding the survey and immense logistical support; the Alfred P. Sloan Foundation, the National Science Foundation (NSF), and the Deutsche Forschungsgemeinschaft (DFG) for generous financial support; Stefan Bender for helping to kickstart the project; Guilherme Lichand and the MGov team for solving the logistical challenge of conducting a survey via SMS; many brave RAs at the IAB, Berkeley and BU; our anonymous sample of UI experts for the Forecasting Survey; as well as Alan Krueger and Andreas Mueller who gave us the inspiration and many useful tips and advice. We also would like to thank Isaiah Andrews, Balazs Reizer, David Card, Raj Chetty, Simon Jaeger, Kory Kroft, Bruce Meyer, Robert Moffitt, Matthew Notowidigdo, Alexandra Roulet, Amelie Schiprowski, Johannes Spinnewijn, as well as seminar participants at Boston University, the Applied Micro Workshop in Paris, Carnegie Mellon, the NBER SI 2020, UCL, the CEPR Labor Conference 2021 and the University of Edinburgh for many helpful comments and suggestions. All errors are our own. 


\section{Introduction}

To tell apart different models of job search, the key piece of evidence is typically the path of the hazard rate from unemployment to employment. The evidence from administrative data sets suggests three common patterns, from the US (Ganong/Noel, 2019) to Spain (Domenech/ Vannutelli, 2019), from France (Marinescu/Skandalis, 2021) to Slovenia (Boone/van Ours, 2012): (i) the hazard rate from unemployment declines in the initial months of unemployment; (ii) it increases near expiration; (iii) it declines again following expiration, creating a spike at UI exhaustion. ${ }^{1}$ We find those same patterns in Germany for recipients with potential unemployment duration ranging from 6 to 15 months (Figure la). ${ }^{2}$

As well-established as these patterns are, it is not obvious how to translate them into job search models because of the role of unobserved heterogeneity and other confounders. Does the decline in job finding rate in the initial months reflect workers discouragement, or the fact that more able workers get jobs faster? Does the spike of the hazard rate at exhaustion reflect increased search intensity, or previous offers that the workers extended, as in the storable offer models (Boone/van Ours, 2012)? With aggregate hazard rates, one can attempt to separate the different models, but the ability to do so is ultimately limited by the fact that we do not observe the path of search effort within worker, only the aggregate composition. Ideally one would like to have a within-worker measure of search intensity over the spell.

In this paper, we provide evidence on search intensity from a panel survey of unemployed workers in Germany. In doing so, we build on the pioneering work of Krueger/Mueller (2011, KM) who surveyed a panel of unemployed workers in New Jersey in the wake of the Great Recession. As important as the lessons from KM are, they are limited in the ability to address the questions above by the repeated UI benefits extensions in their time frame.

We survey 6,349 unemployed workers in Germany for 18 weeks between November 2017 and November 2019. Throughout, the economic environment is stable, with the unemployment rate between 5 percent and 6 percent. To disentangle the survey responses from time or cohort effects, we stagger the start of interview over 20 months, and we randomize the time of contact during the spell, e.g., in months $2,5,8,11$, or 13 . We contact groups with potential benefit durations (PBD) of $6,8,10,12$, and 15 months. The variation in PBD of $6,8,10$, or 12 months depends on the length of contributions to the UI system, while the difference between 12 or 15 months depends on an age discontinuity (as studied by Schmieder/Trenkle, 2020).

\footnotetext{
1 Moffitt (1985) and Meyer (1990) were the first to clearly document the sharp increase in the exit hazard approaching UI exhaustion, while Katz/Meyer (1990) is to our knowledge the first paper to show the increase as well as the decrease after exhaustion.

2 For a recent survey on the effects of UI on job finding rates see Schmieder/von Wachter (2016).
} 
Instead of conducting a phone or web survey, we use SMS messages, a survey method used to some extent in developing countries (e.g. Ballivian et al. 2015; Hoogeveen et al. 2014; Berkouwer/Dean 2019) and epidemiological research (e.g. Kuntsche/Robert 2009; Johansen/Wedderkopp 2010) but a novelty, as far as we know, in our context. This survey feature was chosen to limit exhaustion and attrition. We contact 86,673 unemployed workers with a letter letting them known of the upcoming text message; a few days later we send text messages asking for consent to participate in a survey. Among the 7,805 respondents who consent, the 6,349 workers who are unemployed at time of contact constitute our main sample. The respondents receive text messages twice a week, on Tuesday and Thursday, with a question on search effort (translated from German): "How many hours did you spend searching for a job yesterday? For example, looking for job-postings, sending out applications or designing a cv. Please reply with the number of hours, e.g. "0.5", or "2". If, for whatever reason, you did not look for a job simply respond with " 0 "'.

Our measure of search intensity is the answer to this question for the individuals who are still unemployed (which we determine combining information from administrative data and survey responses). We document four encouraging features of this measure. First, the average number of minutes of job search, 85 minutes per day, is comparable to the average search intensity in other studies. Second, the measure of search effort displays no obvious time trend and only limited seasonality, making the use of time controls of limited importance. Third, it responds strongly to plausible determinants of search intensity: the measure declines by 75 percent upon receiving a job offer, and by 30 percent on a holiday.

The fourth validation is the most critical for our design, since it enables us to focus on withinperson search intensity. Compare two groups of survey participants who are unemployed in month 5 of potential duration; the first group was randomized to receive the invitation to participate on month 2, while the second group on month 5 . We would like the two groups to have similar reported search intensity, so that when the survey started, conditional on month of unemployment and current unemployment status, is not material to the response. This property could fail because, for example, individuals start off over-reporting the number of hours searched but become more truthful as the survey goes on. We document that in our sample there is no systematic difference in average search effort between the two groups, that is, the between-worker and within-worker estimates are comparable. This is a different pattern than in the KM survey. While we cannot tell for sure, the SMS format, making response easy and not time-consuming, likely contributed to this pattern in our survey.

Having established these desirable properties, we turn to three key pieces of evidence. First, we document the path of search effort in the initial months, far from exhaustion. The standard model predicts an increase, while other models predict a decrease, say due to discouragement or habituation. Second, we provide evidence on the path of search effort near exhaustion. The standard model implies an increase in search up to exhaustion, with a con- 
stant effort thereafter. A reference-dependent model with backward-looking reference points (DellaVigna et al., 2017) also suggests an increase up to exhaustion, but a decrease thereafter. Third, we focus on the role of storable offers. Namely, we test whether individuals who report getting a job near benefit expiration seem to time the job start date to coincide with UI exhaustion. In the online appendix we compare these results (as in DellaVigna/Pope, 2018 and DellaVigna/Pope/Vivalt (2019)) to the average prediction of 35 experts on job search.

For the first finding, we consider the intensity of search effort from month 2 (as early as we could survey unemployed respondents) to month 6 , excluding the group with 6-month PBD. The search intensity stays flat, from 88 minutes in month 2 to 87 minutes (s.e. $=2.8$ minutes) in month 6 . This contrasts with a sharp decrease in the hazard rate from unemployment from 12 percent to 7 percent over the same unemployment length. This suggests that the decline in hazard rates is unlikely to be due to a discouragement effect.

For the second finding, we focus on search effort around UI exhaustion. Search effort increases by 6.5 minutes (s.e.: 2.0 minutes) up to expiration, and then decreases by 4.9 minutes (s.e.: 1.9 minutes). Thus the "spike" in hazard is matched by a similar "spike" in search intensity, even if, in percent terms, the increase in minutes searched is smaller.

For the third finding, as a proxy for storable offers, we compute the average number of days between the (reported) job offer and job start. This gap is only slightly larger for the individuals starting their job at UI expiration compared to individuals starting jobs on other months. We also find no evidence of storable offers using an alternative measure.

We then turn to whether a model of job search can quantitatively explain our findings on the path of search effort throughout the UI spell, as well as the observed reemployment hazard. We generate reemployment hazard rates using administrative data for a comparable population as the survey sample. Using both the search effort and hazard paths as target moments, we estimate via minimum distance a model with costly search effort and an optimal consumption choice. As far as we know, this is the first estimate of a job search model with information on both the inputs (the search intensity) and the outputs (the hazards). ${ }^{3}$

Building on DellaVigna et al. (2017), we compare a standard job search model with unobserved heterogeneity with a model with loss aversion relative to recent average income. In the reference-dependent model, unemployed individuals search especially hard when current consumption lags recent income, for example at $\mathrm{UI}$ expiration, as loss aversion makes unemployment especially painful; over time, however, they get habituated as the reference point adapts, and thus the search intensity declines. The speed of the reference point adaptation is a key model parameter which we estimate. We also consider models of duration depen-

3 Gautier/Moraga-González/Wolthoff (2016) calibrate a model of search costs on Dutch data on number of applications and Potter (2021) estimates a search effort model on the KM data. 
dence in search costs, to capture for example worker discouragement. Across these models we assume present-biased discounting; models with exponential discounting lead to similar qualitative results, but have a worse fit.

The standard model and the reference-dependent model fit similarly well the hazard moments and the search effort in the initial months, but they differ in the fit of the search effort near UI expiration. The reference-dependent model fits well the increase and then decrease of effort near expiration, with the decrease explained by the reference-point adaptation. The standard model, instead, fits well the increase but cannot explain the subsequent decrease. The standard model can match this latter fact only if we allow search effort to become more costly or less productive over time, a form of duration dependence which captures, for example, worker discouragement. This duration-dependent model in fact fits the data better than the reference-dependent model. We stress though that we do not have direct evidence on the time pattern of duration dependence and the fit of this model is sensitive to the assumed pattern.

Other models and factors could affect our conclusions. A model with a fixed pool of vacancies (as discussed in Faberman/Kudlyak, 2019) to search could generate a decrease in search effort post expiration, as workers sampled most available jobs by the deadline; however, this model would predict a dip in search effort after expiration, rather than the observed smooth decrease. Temporary layoffs of workers who are later recalled (as in Katz, 1986; Katz/Meyer, 1990) could explain the spike in hazards at expiration, but recalls are relatively uncommon in Germany and do not affect the hazard rate.

The paper is related to other papers measuring search effort over the unemployment spell. As mentioned above, we build on the survey of unemployed workers in KM, but unlike in KM we are able to examine search effort at expiration. Two papers measure search effort with activity on online postings: Marinescu/Skandalis (2021) using data from activity on the web portal for unemployed workers in France documents a similar increase and decrease of search effort near expiration; Faberman/Kudlyak (2019) using activity on an online job search platform in the US cannot study search effort at expiration, but, like us, does not find evidence of a decrease in search effort in the initial months. We view the two forms of evidence as highly complementary. The survey-based measure is based on a self-report, unlike the administrative measure in the job portals, but has the advantage that it covers all forms of job search, not just one particular, and infrequent, job search activity. ${ }^{4}$

The paper is also related to papers bringing to bear evidence on job search models (e.g. Card/ Chetty/Weber, 2007; Nekoei/Weber, 2017; Kolsrud et al., 2018; Belot/Kircher/Muller, 2019; Ganong/Noel, 2019) and the disincentive effects of UI (Rothstein, 2011; Lalive/Landais/Zweimüller,

4 We present a detailed comparison to Marinescu/Skandalis (2021) in Online Appendix E. Other related papers are Lichter/Schiprowski (2020) and Arni/Schiprowski (2019). 
2015; Johnston/Mas, 2018; Leung/O'Leary, 2019; Le Barbanchon/Rathelot/Roulet, 2019). The evidence from within-person search effort complements the traditional information on hazard rates from unemployment. Indeed, in our context the hazard rates would be insufficient to distinguish between models. Our finding of a flat within-person profile in search effort is consistent with evidence from Mueller/Spinnewijn/Topa (2021) suggesting that the decline in hazard is more likely due to unobserved heterogeneity than true duration dependence. Our findings are consistent with the reference-dependent explanation of evidence from a reform in Hungary (DellaVigna et al., 2017), with comparable degrees of loss-aversion, though a longer adaptation period.

The paper is also related to the field evidence on reference dependence (e.g. Sydnor, 2010; Barseghyan et al., 2013; Allen et al., 2017; Rees-Jones, 2018; O'Donoghue/Sprenger, 2018; Barberis, 2018). Our evidence points to backward-looking, adaptive reference points (e.g. Thakral/Tô, forthcoming), for example because of memory (Bordalo/Gennaioli/Shleifer, 2020).

Methodologically, our paper highlights the benefits of using SMS messages to run surveys. Respondents in our sample participated twice a week for 4 months, with relatively low attrition, and at a moderate cost. Relative to traditional methods-phone and online surveys-, SMS-based surveys lend themselves to cases with few, simple questions and answers, like ours.

\section{Survey Design and Setting}

The target group for the survey are prime-age recipients of UI benefits in Germany. The German UI system has been studied extensively (e.g. Fitzenberger/Wilke, 2010; Schmieder/von Wachter/Bender, 2012; Caliendo/Tatsiramos/Uhlendorff, 2013; Dlugosz/Wilke/Stephan, 2014; Schmieder/von Wachter/Bender, 2016; Altmann et al., 2018). Individuals who become unemployed and have worked at least 12 of the 30 previous months are eligible to UI benefits at a replacement rate of 60 percent (67 percent for workers with children). UI claimants can receive benefits up to the PBD, which is determined by the work history. While on UI, unemployed workers regularly meet with caseworkers who provide support, monitor job search efforts, and may assign workers to active labor market programs (see Schmieder/Trenkle, 2020, for details). After UI benefits are exhausted, workers may claim a second tier of benefits called "Unemployment benefits 2" (UI-2), a means-tested program on the household level and substantially less generous than regular UI benefits. 
The survey was funded and conducted by the Institute of Employment Research (IAB), the research institute of the German Federal Employment Agency. ${ }^{5}$ Since the UI system is overseen by the Federal Employment Agency, the IAB has direct access to the administrative data on UI claims and the work history of the claimants. Integrating the survey with the administrative data provides three advantages: a) the administrative data allows for a targeted sample, such as workers close to UI exhaustion, and checks for the representativeness of the sample, b) the administrative data provides extensive demographic and labor market information that does not have to be obtained via survey; and c) participants can be followed even after the conclusion of the survey.

The first wave of UI recipients was contacted in November 2017 (Figure lla illustrates the timing). Through the IAB, we obtain the universe of UI recipients with about a 3-week delay. Among the UI claimants with recorded cellphone numbers (about 80 percent of claimants), we selected a (stratified) random sample of UI recipients, for whom we obtained addresses from the UI data. The contacted individuals received a letter and a flyer in the mail (see Figure A.1 and A.2) explaining the format of the survey, the anonymity of the responses, and the incentives for participation (20-euro Amazon gift vouchers for participating for the full survey duration). ${ }^{6}$ After receiving the letter on a Thursday (approximately), the UI recipients are contacted on the following Tuesday via SMS. ${ }^{7}$ This initial SMS contact asks for consent to participate in the survey and to link the responses to the administrative data. If the person consents, we ask the first question on job search effort. For the next 18 weeks, we contact the participants each Tuesday and Thursday.

The sample for this initial (and each subsequent) wave consisted of 2 distinct groups: 'shorteligibility' workers, with potential benefit durations (PBD) of 6, 8 or 10 months, and 'longeligibility' workers, with 12 or 15 months of PBD. The short-eligibility group consists of workers age 28 to 55 who have at least 12 , but strictly less than 24 contribution months in the previous 5 years. In this group having at least 16 contribution months increases PBD from 6 to 8 months and having at least 20 contributions months increases PBD to 10 months. The long-eligibility group consists of workers between age 45 and 55 with at least 30 months of UI contributions in the previous 5 years. Workers within this group who were younger than 50 at the time of UI claiming have 12 months of PBD, and 15 months of PBD otherwise.

Considering the entire sample of workers entering unemployment in our approximate sample period, the hazard rates into employment (Figure la) display the familiar patterns with

5 The direct costs of conducting the survey was born by the IAB. Additional funding for researcher time and research assistance positions came from the Alfred P. Sloan Foundation, the German Science Foundation (DFG) and the US National Science Foundation (NSF).

6 Once an individual consents, she receives a 5 Euro Amazon gift voucher (in form of a Code via SMS). If the individual keeps responding to questions, she receives another 5 Euro voucher after the first 2 months and a final 10 Euro voucher after completing the entire 18 weeks. About 60 percent of vouchers were redeemed as of December 2019, 2 months after the end of the survey (see Table A.1).

7 The technical aspect of sending SMS messages and processing responses was run by Guilherme Lichand at the University of Zurich and his company 'MGov' (now 'Movva'). 
decreases in hazard from month 2 onward, and a spike near expiration. To show that these patterns are causal, Figure lb shows the regression discontinuity estimates around the age cutoff that determines whether individuals have 12 or 15 months of PBD, displaying a sizable spike in the hazard rate near exhaustion. Regression discontinuity estimates comparing durations of 6 versus 8 month, and 8 versus 10 months display similar spikes (Figure A.3).

Recalls could explain the spike in the hazard at exhaustion if employers strategically choose recall dates to coincide with benefit expiration (Katz, 1986 and Katz/Meyer, 1990), and such recalls are important in settings such as the US (50 percent recall rate, Fujita/Moscarini, 2017) or Austria (35 percent recall rate, Nekoei/Weber, 2015). In contrast, in our sample the share of UI recipients returning to their previous employer is only about 10-15 percent and the hazard rates excluding recalls are similar (Figure A.4).

In addition to sampling by PBD strata, we also stratify by elapsed nonemployment duration. For example, for the PBD=12 group, we contact some individuals at the end of the 2 nd month after claiming UI, and others at the end of the 5th, 8th, 11th, and 13th month. The weights (shown in Table A.2) are chosen to oversample individuals close to UI exhaustion. We call each Wave x PBD x D cell a "Panel". Figure Ilb shows the 5 panels that start in November 2017 for the $P B D=12$ group, each running for 4.5 months until March 2018.

In each month until the last wave in July 2019, we contacted workers following the same design. Thus, a cohort of workers with 2 months of unemployment in November of 2017 was contacted again in February 2018, now in the $D=5$ months panel. While we do not contact the same individual more than once, this overlapping panel design allows us to trace out search effort for a cohort for much longer than the 18 survey weeks.

While the first 2 waves served as a pilot with only about 500 contacted individuals, the next waves had 3,000 and, starting in August 2018, 5,000 contacted individuals per wave. The sequence of 22 monthly waves (see details in Table A.3) allows us to explore the role of calendar effects and time trends. ${ }^{8}$ Since we contact each wave on a single day of the month, there is some variation (up to 2 weeks) within each PBD $\times$ D cell in the exact time since entering $\mathrm{UI}$ at the time of contact. For expositional ease, we treat every individual in a PBD x D cell as if their unemployment duration at the time of UI entry is exactly D months.

Table I shows an overview of our sample. Column 1 shows average characteristics for all individuals who received UI benefits during our survey period. Workers without prior UI spells and no unused UI eligibility are eligible for exactly $6,8,10,12$, or 15 months of UI benefits (or even more if they are older than 55) at the beginning of their UI spell. We target UI claimants who, at the time of sampling, have these exact levels as PBD. We also restrict to individuals with a cell-

8 In the KM survey individuals were all contacted in a single wave, so that the UI entry date and the unemployment duration at survey start are essentially collinear. 
phone number and a valid address, that are neither sanctioned nor in a training program at time of data retrieval. In addition, we restrict to age 28 to 55 at time of UI start ( 45 to 55 for the 12 and 15 PBD groups). Column 2 shows individuals that satisfy these sampling requirements and column 3 shows the characteristics of the 86,673 individuals contacted with a letter and then SMS messages. The differences between column 3 and 2 are due to the weights different PBD $x$ D groups receive in our stratified sample.

Of the individuals contacted, 9 percent agreed to participate (Column 4), a response rate comparable to the one in the KM survey (reported in the bottom row in Table II). Participation is clearly not random (Column 3 versus 4). While the age composition is similar, participants are less likely to be of foreign nationality (16 percent vs. 27 percent), are more educated and more likely to be women. ${ }^{9}$ Below, we provide robustness results re-weighting by these observables. The response rate across the different PBD groups is relatively similar.

We complement the summary statistics for this sample with information on transition from unemployment and hazard rates. Figures A.5 and A.6 display the transition into the various states - such as entry into UI-2-by week of unemployment. Figure A.8 shows that the hazard rates for contacted versus respondents are quite comparable and Figure A.7 shows that the hazard patterns are similar to the ones in the larger sample (Figure la). Using the hazard information, we can also test whether contacting unemployed workers for the survey had an effect on the search effort, perhaps acting as a reminder. Figure A.9 and Table A.5 show that there is no evidence of an impact of survey contact on the hazard rate.

Due to the delay of 3-4 weeks between the most recent snapshot of the UI data and the contact date, 19 percent of participants have already found a job at the time of contact. We were concerned that participants might respond that they found a job in order to cut the survey short. Thus, we make it clear that the survey continues for the entire 18 weeks whether or not the participants are employed. Still, our results focus on the 6,349 participants who are unemployed at the beginning of the survey and respond to at least one question on job search (Column 5). To determine unemployment status, we combine the reported unemployment status in the survey and administrative data on job-finding, as detailed in Appendix D.

Attrition is low: 70 percent $(4,571)$ of the initial participants stay in the survey until week 18 and of those who stay 57 percent are still unemployed (Column 6). The individuals who participate to the end have characteristics similar to the initial participants. ${ }^{10}$ The attrition is similar across cohorts and does not seem to change discontinuously around UI expiration (Figures A.11 and A.13a). Further, the probability of responding to the search effort question, condi-

9 Table A.4 directly compares participants with non-participants and provides tests for equality. Due to sample sizes almost all differences are statistically significant.

10 Figure A.10 shows that the attrition rate in our survey is substantially lower than in the KM study (about 50 percent by week 12). Furthermore, while KM report that respondents completed around 40 percent of the weekly interviews, in our data participants responded to around 78 percent of weekly job search questions. 
tional on no attrition, is fairly constant over the sample (Figures A.12 and A.13b) and does not vary much depending on the most recent reported search effort (Table A.6). Finally, the hazard rate is comparable for full participants and attriters (Figure A.14).

In addition to the biweekly questions on minutes spend on job search, we also ask one additional question each Tuesday, rotating between 4 questions:

1. Target wage: Please recall the last job you applied for. What do you think is the typical monthly wage for such a job in Euros?

2. Life satisfaction: Taken all together, how satisfied are you with your life? Please reply with a number between 1 (not satisfied at all) and 5 (very satisfied).

3. Search intensity: How hard did you search for a job over the last week? Please reply with a number from 1 (no search) to 10 (very hard search).

4. Job Found: We would like to know if your job search was successful. Please reply with 1 if you found a job and 2 if you are still searching for a job.

If a participant responds to the last question with " 1 ", we ask 3 follow up questions: a) what is the start date of the new job; b) what date was the offer received; and c) what date was the job accepted. Figure A.15 displays the sequence of the questions, while Table A.7 shows the complete text of all questions in German with English translation.

\section{Validating the Survey Responses}

\subsection{Basic Patterns of Search Effort Responses}

The question on job search effort, asked each Tuesday and Thursday for 18 weeks, is:

How many hours did you spend searching for a job yesterday? For example, looking for job-postings, sending out applications or designing a cv. Please reply with the number of hours, e.g. "0.5", or " 2 ". If, for whatever reason, you did not look for a job simply respond with " 0 ".

To deal with outliers (which may stem from a typo), we drop answers above 15 hours ( 0.1 percent of observations) and winsorize the responses above 6 hours (2 percent of observations). As Figure IIla shows, almost all responses are at multiples of 30 minutes, with the most common responses being no search on the previous day (32 percent) and 1 hour (18 percent). 
Figure IIIb shows that the average search effort by day over the duration of our survey displays no obvious time trend and only limited seasonality. Encouragingly, the mean time spent searching ( 85 minutes) is comparable to the average search intensity in the KM survey ( 70 minutes on weekdays), in the Survey of Consumer Expectations supplement (77 minutes, Faberman et al., 2017) and is somewhat higher than in the American Time Use Survey (48 minutes, Krueger/Mueller, 2010).

As a first validation check, we investigate how search effort changes on public holidays, where search effort is likely lower because of holiday activities and since employers may not be reachable. While we paused the survey during the Christmas / New Year period, we did ask questions on days following a national holiday, such as Easter Monday or Labor Day (May 1st). On these days, indicated in Figure IIIb with dashed lines, there is a clear dip in search effort. An event-study analysis (Figure IVa) shows a dip of around 30 minutes on a holiday. ${ }^{11}$ This drop is very similar in the KM survey (Column 5 of Table A.8 and Figure A.17a).

As a second validation check, we consider the 3,077 respondents for whom we observe a job finding date after the start of the survey. The job finding date combines information from the survey and the administrative data (see appendix D for details). As Figure IVb shows, search effort is stable at 100 minutes before job acceptance, and it falls sharply to 30 minutes thereafter. This pattern is once again similar in the KM sample (Figure A.17b).

As a third check, Figure IVc shows how search effort evolves around the start of a job, splitting by the gap in days between the job offer and the job start. Workers who receive an offer and start a job shortly after (within less than 9 days) have the sharpest drop in search effort. If workers received an offer more than 26 days before the job start, search effort falls already around 2 months prior to the job start. ${ }^{12}$

As a fourth check, we measure whether the reported search effort is correlated with a higher job finding rate in the next months. Table A.9 shows that this is the case at least in the crossworker regressions, as documented also in $\mathrm{KM}$.

While the mean search effort is our key measure, we also consider additional variablesdifferent quantiles of the search effort measure, a qualitative measure of job search, a target wage, and a life satisfaction measure. We thus examine whether these measures pass the validation around job acceptance. In Figure A.18 we show a strong response to job acceptance of two key quantiles of search effort: any search and high search (search >=240 minutes). In Figure A.19 we show that similarly the qualitative search effort measure decrease strongly around job acceptance, and that life satisfaction rises sharply. We do not instead de-

\footnotetext{
11 Table A.8 shows that search effort drops less for less important holidays, by around 17 minutes on regional holidays and by about 5 minutes during school vacations.

12 Figure A.16 shows the distribution of the offer-start gap. It also shows that most of this gap comes from a gap between the job acceptance date and the job-start date.
} 
tect any movement in the (log) target wage measure, suggesting that this measure likely does not carry much information. We thus de-emphasize the target wage variable.

Overall, search effort - both our main measure and the additional ones, except for the target wage - responds in sensible and intuitive ways to exogenous events like holidays and endogenous events like job acceptances and job offers.

\section{Systematic Reporting Bias}

A different challenge is that there could be systematic reporting bias over the course of the survey. For example, respondents might initially be embarrassed to admit not searching for a job but this 'social desirability bias' may decline over time. Respondents might also develop survey fatigue and default to answer '0' (or something else) as the survey goes on.

We now consider this issue, with additional detail in Online Appendix D. Panel A of Table II presents regressions of search effort (while unemployed) on the number of months of unemployment. The first columns ("between") use only the first response of each individual and the variation is thus entirely cross-sectional, with controls added in Column 2. Column 3 ("within") uses all the responses but controls for individual fixed effects, thus presenting a within-person estimate. The point estimate for the between estimators is -0.67 minutes per month of job search, -0.46 with controls. The within estimate in column 3 is similar, with a point estimate of -0.20 , not statistically significantly different from the between estimate.

These findings are in sharp contrast to the corresponding specifications in $\mathrm{KM}$ which we replicated with the publicly available data in Columns $4-6 .{ }^{13}$ While the between estimates in KM show a slight increase in column 4 (1.10 minutes per month), the within estimate in Column 6 implies a 10.95 minute decline per month. This discrepancy shows up as a seesaw pattern in KM Figure 3 (integrated as Figure A.20): each cohort starts with high search which subsequently declines until the start of the next cohort. This discrepancy makes it hard to know whether search effort is in fact declining or flat throughout the spell, as the within-person estimates appear affected by systematic reporting bias.

The corresponding figure in our data, Figure $\mathrm{V}$, shows that subsequent cohorts largely line up, i.e. the next cohort on average starts at a level of job search where the previous one ended.

We also conduct a direct test of reporting bias. Within a cohort of individuals who become unemployed at the same time and with the same PBD, it is random when a person is sampled.

13 This corresponds to Table 2 in KM. In the paper the regressions add some controls from administrative data that are not publicly available which yields small differences to our results. 
Consider two individuals with the same UI entry date $T^{U I}$, the same PBD $P$ at a time $t$, but sampled at a different survey contact date $T^{\text {contact }}$. In the absence of survey reporting bias, how long an individual has been on the survey $t-T^{\text {contact }}$ should be uncorrelated with search effort $s_{t}$ : $\operatorname{Cov}\left(s_{t}, t-T^{\text {contact }} \mid t, T^{U I}, P\right)=0$. Indeed, Panel B of Table II shows no statistically significant impact of the number of months in the survey on the reported search effort. ${ }^{14}$

We believe that the simplicity of the SMS method made responding easy and minimized the (true or perceived) incentives to simply respond with " 0 ", thus avoiding systematic reporting bias. While we cannot rule out a potential bias in levels (e.g. search effort might always be overstated by 20 percent), any such bias does not appear to vary systematically over the interview. Thus we use the within-person variation in search effort to examine how search varies throughout the unemployment spell and around UI exhaustion.

Table A.11 presents the same test as in Table II, Panel B for the additional job search variables. Unlike for our main measure, the qualitative search intensity and some of the quantiles of the main measure (such as whether the person searched at least 240 minutes) display a seesaw pattern over the survey. Thus, when we present these robustness results, we present also results adjusted, to a first approximation, for this survey trend.

\section{Job Search over the Unemployment Spell}

We now turn to three key pieces of evidence. First, we document the path of search effort in the initial months, far from exhaustion. The standard model predicts an increase, while other models predict a decrease, say due to discouragement or habituation. Second, we provide evidence on the path of search effort near exhaustion. The standard model predicts an increase up to exhaustion, with a constant effort thereafter. A reference-dependent model with a backward-looking reference point (DellaVigna et al., 2017) also suggests an increase up to exhaustion, but a decrease thereafter. For these analyses, we use the search effort responses, excluding individuals after the date at which they are no more unemployed.

Third, to test for the role of storable offers, we examine whether individuals who report getting a job near benefit expiration are more likely to have lower search effort in the weeks

\footnotetext{
14 In Table A.10 we present this same test for some of the key robustness samples which we discuss later. Notice that since KM had a single contact date, there is no variation in $t-T^{\text {contact }}$ conditional on $t$ and $T^{U I}$ and the test cannot be performed directly in their data.
} 
beforehand. In the same spirit we test whether individual who receive job offers before $\mathrm{UI}$ exhaustion delay the job start date to the exhaustion point.

\subsection{Job search at the beginning of the unemployment spell}

For the first finding, we consider the intensity of search effort from month 2 (as early as we could survey unemployed respondents) to month 6 , excluding the group with UI expiration at month 6 . Figure $V$ presents the disaggregated evidence for each of the five PBD groups $(6,8,10,12$, and 15 months), for each of the sampling schemes. In all five PBD groups, the unemployment duration in the initial months is fairly flat, with a slight decrease for PBD of 8 and 15 months and a slight increase for PBD of 12 months.

In Table III we aggregate across all the PBD durations (except for PBD of 6 months). We compare the search intensity in months 3, 4, 5, and 6, with search intensity in month 2 (the omitted category). Columns 1 and 2 display the estimates from a cross-sectional regression, combining within-person and between-person variation, with demographic controls added in Column 2. Both specifications indicate a flat profile of search effort. In Column 3 we add person fixed effects, thus focusing on within-person search effort. Finally, Column 4, our benchmark specification (reproduced in Figure VIc), also adds some basic time controls-fixed effects for question asked on Thursday versus Tuesday and calendar month fixed effects. ${ }^{15}$ These specifications confirm the finding of a precisely-estimated flat search profile: we can reject a 5 percent ( 4.8 minutes) decrease in search intensity by month 6 relative to month 2 . We also find a flat profile (with some evidence of an increase in search effort) if we consider the search effort up to month 10 for the PBD 12 and 15 (Table A.12).

How do these patterns compare with the patterns in the exit hazard from unemployment? Figure Vla displays a weighted hazard rate over PBD groups, matching the share of PBD groups in Figure VIc. Given the timing evidence in Figure IVb-c, we compare the patterns of job search to patterns in the hazard one month later. The flat path in search effort contrasts with a sharp decrease in the hazard rate from 12 to 7 percent over the same unemployment length. This suggests that the decline in hazard rates is unlikely to be due to a discouragement effect and may be due to unobserved heterogeneity.

15 We cannot add a full vector of date fixed effects, given the presence of individual fixed effects in the regression, for the usual inability to non-parametrically separate out cohort-time-age fixed effects. 


\subsection{Job search around UI exhaustion}

For the second finding, we focus on search effort in the 4 months around the UI exhaustion. The raw data in Figure $V$ shows an increase in search intensity up to expiration (captured as month T-1) for all PBD groups other than for PBD of 6 months. Following benefit expiration, search intensity declines for all PBD groups other than for PBD of 15 months.

Table IV presents the evidence for search intensity, compared to month $\mathrm{T}-1$, the last month of receiving benefits, for cross-sectional (Columns 1 and 2) and within-person specifications (Columns 3 and 4), yielding qualitatively similar results. In the benchmark specification (Column 4), search effort increases by 6.5 minutes (s.e. $=2.1$ minutes) in the 3 months leading up to expiration, and then decreases by 4.9 minutes (s.e. $=1.9$ minutes) in the ensuing 3 months.

Figure VId displays the point estimates from Column 4, comparing them to the parallel estimates on the time path of the hazard rate (Figure VIb). The "spike" in hazard is matched by a similar "spike" in search intensity, even if, in percent terms, the increase in minutes searched is clearly smaller. Unlike our conclusions in the previous section, this suggests that the hazard patterns at expiration can be accounted for by shifts in search effort.

\subsection{Robustness}

We present a battery of robustness checks in Table $V$ and Tables A.13-A.16 for these two key results. All estimates include person fixed effect and time controls, as in our benchmark.

Constant Cohorts. The key results are identified by within-person shifts in search effort, given the person fixed effects. Yet, there can still be compositional effects as the sample responding to the survey changes over time. We address this in two ways. First, in Column 2 of Table $V$ and of Table A.13 we restrict to "full participants" who respond (and stay unemployed) for the full 18 weeks. Second, in Figure VI(e)-(f) we go further and report the search effort for "fullparticipants" cohorts surveyed early in the UI spell, and around UI exhaustion, where each line corresponds to a single cohort thus creating a fully balanced panel. The estimates from these smaller samples, while noisier than the benchmark ones, replicate our key findings.

Sample Inclusion. We consider alternative definitions of unemployment status. While for the main specification we combine information from survey responses and from administrative data, we can define unemployment status using only administrative data, or only survey data. We can also exclude individuals who have UI-2 at the beginning of the spell. The results are similar with these alternative definitions (Tables A.14 and A.15). 
Shifts in UI expiration. The UI benefit duration (PBD) may change over the duration of the spell as a result of participation in active labor market programs, typically leading to an extension of benefits. So far, in the intent-to-treat spirit, we have used the PBD as measured at the start of the spell, but to the extent that the actual PBD differs, this would likely bias us against finding a decline of effort at $\mathrm{UI}$ expiration, given that the revisions typically involve a longer duration. To deal with this issue, in Column 3 of Table $V$ and of Table A.13 we restrict the sample to workers for which no shifts in UI duration took place. As expected, we find even stronger evidence of a decline in effort post expiration. We find a similar pattern using the whole sample but using the revised PBD to compute the timing of expiration (Table A.15).

Representativeness of Sample. Survey participants are more likely to have higher education, to be German citizens and female, compared to non-participants (Table I). Thus, we reweight to match the contact sample (Column 4 of Table $V$ and of Table A.13), finding similar results. In Tables A.17 and A.18 we present the results split by demographics. We find the same qualitative patterns across the groups, though some groups display more evidence of an increase up to exhaustion, while other more evidence of a decrease ex post.

Coding of Search Measure. In the benchmark search measure, we ignore cases of non-response. One may worry that non-response is more common when the worker did not exert search effort. In Column 5 of Table V and of Table A.13, we code as zero effort instances of nonresponse, provided that the workers give later responses; the results are very similar.

In Tables A.14 and A.15 we consider several alternatives to code search intensity. Our main measure implicitly gives more weight to frequent responders. As an alternative that does not have this property, we average all the responses of a respondent within a 2-week period and run the regressions at this bi-weekly level. Next, we vary the top-coding to a lower threshold at 240 minutes or to a higher threshold. Finally, one may worry that the search measure is biased if unemployed workers start responding always in the same way (e.g., "1 hour"). We thus exclude strings of at least 5 consecutive identical responses (other than " 0 "). In all these specifications, the results are similar to the baseline ones.

Search Monitoring. An important question is to what extent the decline in search effort post expiration is due to a decrease of monitoring (actual or perceived) and of interactions with the UI system. To address this, we match to the survey data a detailed record of all interactions with a caseworker and letters received from the UI system. We add detailed controls for these variables in Column 6 of Table $V$ and of Table A.13, with the full set of estimates in Table A.16. Contact with a caseworker indeed is associated with higher search effort, as is receipt of a UI letter 2 weeks before. Accounting for these variables, though, has only a minor impact on the estimates. As a separate approach, in Table A.15 we re-estimate the search effort around expiration on the sample eligible for UI-2 after expiration, in which case the monitoring re- 
mains similar even after expiration. The sample is smaller and thus the estimates noisier, but the point estimates are comparable to the main sample.

Experience with UI System. If people are not aware of the benefit level and rules after UI expiration, especially with respect to UI-2, some of patterns around expiration could be related to learning about the system. We thus re-estimate the results on the sample with past experience with UI-2, finding similar results to the benchmark ones.

Time Effects. One may be concerned about two types of time effects. First, there may be common deadlines since UI start, e.g., at 12 months, that affect search effort. In Table A.15 we add as controls fixed effects for months $6,8,10,12$, and 15 since UI start. Second, since we cannot control for a full vector of time fixed effects (due to the inability of separately identifying a linear time and duration trend), the results may be partly driven by changes in labor market conditions over time. In Tables A.14 and A.15, we thus control for the county level monthly unemployment rate. Both estimates are very similar to the benchmark ones.

Different PBD Groups. A legitimate question is whether a single PBD group is responsible for the estimated patterns. We find a fairly constant pattern of search effort initially for all groups (Table A.19). We detect an increase in search effort leading up to the expiration for 3 out of the 5 groups (and a flat pattern for the other 2) and a decrease in effort post expiration for 4 out of the 5 groups, with an increase just for the 15-month PBD group (Table A.20). Thus, the results do not depend on any one PBD group.

RD Design. For the analysis of search effort near expiration, in principle we can use the agebased $\mathrm{RD}$ design to compare the $\mathrm{P}=12$ and $\mathrm{P}=15$ month groups. Figures A.21-A.22 and Table A.21 show that this comparison provides suggestive evidence of an increase in search effort in month 11 of $\mathrm{UI}$ for the $\mathrm{P}=12$ group and conversely in month 14 , consistent with our main results, though with the caveat that this analysis is statistically under-powered.

Quantiles of Search Effort. We now consider different quantiles of the search effort variable, such as the share of workers reporting positive search and the share reporting at least 240 minutes of search. Figure A.23 and A.24 display the disaggregate plot for these variables. Unlike for our main measure, these figures provide evidence of apparent survey bias, as discussed above and documented in Table A.11. Thus, in Tables A.22 and A.23 which replicate the key tables for these quantiles, we display in Panel $B$ the estimates with a linear correction for the survey bias. While the unadjusted estimates display quite different patterns across the quantiles, after adjustment for the survey bias, the results are consistent with the main ones: in the initial months of unemployment the search intensity is flat, or slightly decreasing (Table A.22). Search intensity increases up to expiration (weakly for the any-search measure) and decreases following expiration (Table A.23). 
Additional Search Measures. Figures A.25, A.26, and A.27 display the raw patterns for three additional job search measures (asked only once every 4 weeks): qualitative search intensity (1-10), a target wage (which we transform in logs), and life satisfaction. The qualitative search intensity variable displays a clear within-survey downward trend, documented in Table A.11. After controlling for the survey response bias (Panel B of Tables A.24 and A.25, displayed in Figure A.28), the results for the qualitative search effort measure are consistent with the main ones): the search effort is quite flat in the initial months, and it is increasing up to expiration and (weakly) decreasing thereafter. Life satisfaction is fairly flat in the initial months and does not vary much around expiration. As for the target wage measure, which we do not put much weight on since it does not pass the validation, it decreases slightly up to expiration, as predicted, and then it slightly decreases further. Overall, these results are less clear than the benchmark ones, but this is to be expected given the infrequency of these questions in our sampling, as well as the evidence of some survey response bias.

\subsection{Do job seekers time the start date of a job with the exhaustion of benefits?}

We now turn to our third key finding on storable offers: the spike in the hazard at expiration may be mostly due to unemployed workers who received an offer earlier on in the spell, but opted to delay the start of work until the end of the UI benefit period. As far as we know, while this explanation has been put forward often, there is little direct evidence to it.

We use as measure of storable offers the number of days between the date a job offer was received and when the job started, as reported to us by the workers, capped at 180 days. To the extent that storable offers explain the spike, this delay in starting a job should be larger for individuals who start a job at UI exhaustion, versus individuals who start a job before, or after, exhaustion. As Figure VIIa and Table A.26 show, this average delay varies mostly between 25 and 30 days for individuals taking jobs in month -4 to -1 before expiration, and 1 to 2 months after expiration. For the 189 individuals who start a job in the month of UI expiration, this delay is just slightly higher, at 31.7 days. Thus, delay of job start due to storable offers, if any, is quantitatively small or limited to a small share of workers.

As complementary evidence, in Figure VIIb we compare the search effort intensity in the months leading up to the job start for individuals who start a job at expiration, versus individuals who start a job before, or after, UI expiration. To the extent that storable offers are common for the group starting a job at UI expiration, their search effort should taper off sooner. Instead, Figure VIIb shows that the decrease of search effort leading up to job start is independent of when the job start falls, a finding that we replicate also using the three alternative search 
measures in Figure A.29. Thus, the evidence does not support a quantitatively important role for storable offer models in explaining the spike at expiration.

\section{Reconciling the Survey Results with Job Search Models}

To interpret the findings, we estimate a non-stationary job search model (van den Berg, 1990) using as moments both the search effort and the hazard patterns. The model builds on DellaVigna et al. (2017) allowing for reference dependence and present bias, but spells out separately the cost of effort and the productivity of effort. The model has a search effort margin and an optimal consumption choice, but no reservation wage choice. It allows for unobserved heterogeneity in the effort cost and in the search productivity functions.

\subsection{The job search model}

Model Setup. We make several simplifying assumptions. First, jobs last indefinitely once found. Second, wages are fixed, eliminating reservation-wage choices. In each period $t$ an unemployed worker sets the optimal effort $e_{t}$ (e.g. minutes of job search per day). The effort yields with probability $f\left(e_{t}\right)$ a job offer in period $t$, paying a re-employment wage $w$. If the individual accepts the job offer, the job starts in period $t+1$. Search effort is costly, with a cost of effort $c\left(e_{t}\right)$. We assume $c(0)=f(0)=0, c^{\prime}(e)>0, f^{\prime}(e)>0, c^{\prime \prime}(e)>0$.

In each period, individuals receive income $y_{t}$, either UI benefits $b_{t}$ or wage $w_{t}$, and consume $c_{t}$. Consumers can accumulate (or run down) assets $A_{t}$ with a borrowing constraint $A_{t} \geq 0$. Assets earn a return $R$ so consumers face a budget constraint $\frac{A_{t+1}}{1+R}=A_{t}+y_{t}-c_{t}$. The UI benefits $b_{t}$ equal $b_{t}=b$ for $t \leq P$ and $b_{t}=\underline{b}$ for $t>P$. In each period $t$ individuals choose not only the search effort but also the optimal consumption $c_{t}$, yielding utility $u\left(c_{t}\right)$.

The utility from consumption is potentially reference-dependent:

$u\left(c_{t} \mid r_{t}\right)=\begin{array}{lll}v\left(c_{t}\right)+\eta\left[v\left(c_{t}\right)-v\left(r_{t}\right)\right] & \text { if } & c_{t} \geq r_{t} \\ v\left(c_{t}\right)+\eta \lambda\left[v\left(c_{t}\right)-v\left(r_{t}\right)\right] & \text { if } & c_{t}<r_{t}\end{array}$

where $r_{t}$ is the reference point. The utility consists of consumption utility $v\left(c_{t}\right)$ and gain-loss utility $v\left(c_{t}\right)-v\left(r_{t}\right)$. When consumption is above the reference point $\left(c_{t} \geq r_{t}\right)$, the individual derives gain utility $v\left(c_{t}\right)-v\left(r_{t}\right)>0$, which receives weight $\eta$, set to 1 . When consumption 
is below the reference point $\left(c_{t}<r_{t}\right)$, the individual derives loss utility $v\left(c_{t}\right)-v\left(r_{t}\right)<0$, with weight $\lambda \eta$. The parameter $\lambda \geq 1$ captures loss aversion: the marginal utility is higher for losses than for gains. The standard search model is nested in this model for $\eta=0$.

The reference point is the average income over the $N \geq 1$ previous periods:

$r_{t}=\frac{1}{N} \sum_{k=t-N}^{t-1} y_{k}$

The parameter $N$ captures the length of adaption: the longer the $N$, the more an unemployed worker feels the loss utility from being unemployed relative to the earlier paychecks (with $w>b$ ) or, after the end of the UI benefit period, relative to the UI benefit checks. ${ }^{16}$

Value Functions. The unemployed choose search effort $e_{t}$ and consumption $c_{t}$ in each period and (assuming for now an exponential discount factor $\delta$ ) face the value function:

$$
\begin{aligned}
V_{t}^{U}\left(A_{t}\right)= & \left.\max _{e_{t} ; A_{t+1}} u\left(c_{t} \mid r_{t}\right)-c\left(e_{t}\right)+\delta\left[f\left(e_{t}\right) V_{t+1 \mid t+1}^{E}\left(A_{t+1}\right)+\left(1-f\left(e_{t}\right)\right) V_{t+1}^{U}\left(A_{t+1}\right)\right] 6.2\right) \\
& \text { subject to: } c_{t}=A_{t}+y_{t}-\frac{A_{t+1}}{1+R}
\end{aligned}
$$

For the unemployed, the value function depends only on assets $A_{t}$, since the reference point is fully determined by $t$ and thus is not an explicit state variable: $V_{t}^{U}\left(A_{t}\right)$.

For the employed, the value function is $V_{t \mid j}^{E}\left(A_{t}\right)$ for an individual employed in period $t$ and who found a job in period $j$, where the combination of $t$ and $j$ determines the reference point:

$V_{t \mid j}^{E}\left(A_{t}\right)=\max _{c_{t}>0} u\left(c_{t} \mid r_{t}\right)+\delta V_{t+1 \mid j}^{E}\left(A_{t+1}\right)$

Given Equation (6.2) the first order condition for the optimal level of search effort $e_{t}^{*}$ in the case of an interior solution can be written as:

$c^{\prime}\left(e_{t}^{*}\left(A_{t+1}\right)\right)=\delta f^{\prime}\left(e_{t}\right)\left[V_{t+1 \mid t+1}^{E}\left(A_{t+1}\right)-V_{t+1}^{U}\left(A_{t+1}\right)\right]$.

The optimal level equates the marginal cost of effort with the marginal value of effort, which in turn is equal to the marginal productivity of effort, times the difference between the value function of being employed, versus unemployed. Notice that the reference dependence affects the optimal effort though its impact on $V_{t+1 \mid t+1}^{E}$ and $V_{t+1}^{U}$.

\footnotetext{
16 There are alternative assumptions for the reference point, in terms of past consumption or forward looking as in Köszegi/Rabin (2006). DellaVigna et al. (2017) discuss these alternatives. A key advantage of our assumption of an income-based reference point is that it is computationally simpler, given that its path is exogenous, while capturing the key memory-salience motivation for backward-looking reference points.
} 
Given that the function $f(e)$ is monotonic, we can rewrite problem (6.2) as

$\max _{s_{t} ; A_{t+1}} u\left(c_{t} \mid r_{t}\right)-\tilde{c}\left(s_{t}\right)+\delta\left[s_{t} V_{t+1 \mid t+1}^{E}\left(A_{t+1}\right)+\left(1-s_{t}\right) V_{t+1}^{U}\left(A_{t+1}\right)\right]$

where $\tilde{c}\left(s_{t}\right)$ is the composite of the actual cost of effort and the inverse of the production function: $\tilde{c}\left(s_{t}\right)=c\left(f^{-1}\left(s_{t}\right)\right)$. This reformulation implies that the problem can be solved as if the optimization is with respect to the probability of exiting unemployment, $s_{t}$, as in DellaVigna et al. (2017). This also makes it clear that with just data on the hazard rate from unemployment $s_{t}$, one cannot separate out the function $c(e)$ and $f(e)$, as one instead estimates a composite function $c\left(f^{-1}\left(s_{t}\right)\right)$. In order to find an interior solution to (6.5), we assume $\tilde{c}^{\prime \prime}\left(s_{t}\right)>0$, in addition to the previous assumptions (which guarantee $\tilde{c}^{\prime}\left(s_{t}\right)>0$ ).

We extend the model to allow for present-bias, with an additional discount factor $\beta \leq 1$ between the current period and the future. Following DellaVigna et al. (2017) and Ganong/Noel (2019), we assume naiveté: the workers (wrongly) assume that in the future they will make decisions based on regular discounting $\delta$. This assumption simplifies the problem, since we can use the value functions of the exponential agent (given that the naive worker believes she will be exponential from next period). In addition, the evidence on present bias is largely consistent with naivete' (DellaVigna, 2009; Augenblick/Rabin, 2019). The naive present-biased individual solves the following value functions:

$$
\begin{aligned}
V_{t}^{U, n}\left(A_{t}\right)= & \max _{s_{t} \in[0,1] ; A_{t+1}} u\left(c_{t} \mid r_{t}\right)-\tilde{c}\left(s_{t}\right)+\beta \delta\left[s_{t} V_{t+1 \mid t+1}^{E}\left(A_{t+1}\right)+\left(1-s_{t}\right) V_{t+1}^{U}\left(A_{t+1}\right)(\$ .6)\right. \\
& \text { subject to: } c_{t}=A_{t}+y_{t}-\frac{A_{t+1}}{1+R}
\end{aligned}
$$

where the functions $V_{t+1}^{U}$ and $V_{t+1 \mid t+1}^{E}$ are given by equations (6.2) and (6.3) above for the exponential discounters. We thus first solve for all possible values of $V_{t+1}^{U}$ and $V_{t+1 \mid t+1}^{E}$ and then we solve for consumption and search paths given $V_{t+1}^{U, n}$.

We also extend the standard model to model duration dependence in search cost, capturing for example worker discouragement, by assuming that the cost function $c(s)$ can change over the spell, as detailed below.

\subsection{Estimation}

Parametric Assumptions. To bring the model to the data, we introduce a set of additional assumptions. First, we assume log utility, $v(c)=\ln (c)$. Second, we assume a search cost function of power form: $c(e)=k e^{1+\gamma} /(1+\gamma)$, with $\gamma>0$ so the function is increasing and 
convex. Third, similarly we assume that the productivity of effort takes a power form $f\left(e_{t}\right)=$ $\min \left[1, E e^{1+\zeta} /(1+\zeta)\right]$, with $\zeta>-1$ so that the function is increasing. This implies that the composite cost function $\tilde{c}\left(s_{t}\right)$ equals $\tilde{c}\left(s_{t}\right)=\frac{\tilde{k}}{1+\tilde{\gamma}}(s)^{(1+\tilde{\gamma})}$ with $\tilde{\gamma}=\frac{\gamma-\zeta}{1+\zeta}$ and $\tilde{k}=\frac{k}{E}\left(\frac{1+\zeta}{E}\right)^{\frac{\gamma-\zeta}{1+\zeta}}$. To guarantee an interior solution, we need $\tilde{c}^{\prime \prime}\left(s_{t}\right)>0$ and thus $\gamma>\zeta$, that is, the search cost function is more convex than the productivity of effort function. For the case of worker discouragement, we assume $c(e)=k\left(1+\tau_{k} t\right) e^{1+\gamma} /(1+\gamma)$, where $\tau_{k}$ denotes the (percent) increase in search cost per time period $t$ since the start of unemployment $(t=0)$.

Fourth, we model heterogeneity across workers in both the cost of search $k$ and the productivity parameter $E$. For example, when allowing for two types, type 1 has parameters $\left(k_{1}, E_{1}\right)$ while type 2 has parameters $\left(k_{2}, E_{2}\right)$.

Fifth, we make the following assumption about wages and unemployment benefits. The preunemployment wage $w$ equals the average wage for each of the different PBD groups ${ }^{17}$, the re-employment wage equals $0.9 w$, building on evidence in Schmieder/von Wachter/Bender (2016); UI benefits equal $0.635 \mathrm{w}$, and following expiration of the UI system, workers receive welfare benefits equal to 400 euros. Sixth, we assume that individuals start with zero assets and that they earn no interest on savings (given the low-interest rate environment).

The vector of parameters $\xi$ for the standard model are: (i) three levels of search cost $k_{\text {high }}$, $k_{\text {med }}$, and $k_{\text {low }}$, with $k_{\text {high }} \geq k_{\text {med }} \geq k_{\text {low }}$, three levels of productivity of effort $E_{\text {high }}, E_{\text {med }}$, and $E_{\text {low }}$, and two probability weights $p_{\text {low }}$ and $p_{m e d}$; (ii) the search cost curvature $\gamma$; (iii) the productivity curvature $\zeta$; (iv) the time preference parameters $\delta$ and $\beta$. For the referencedependent model, we estimate in addition: $(v)$ the loss aversion parameter $\lambda$; and (vi) the number of (1-month) periods $N$ over which the backward-looking reference point is formed. ${ }^{18}$ For the reference-dependent model we estimate a model with 3 types of heterogeneity, and a model with only 2 types, in which case we remove parameters $k_{\text {high }}, E_{\text {high }}$, and $p_{\text {med }}$. The weight $\eta$ on gain-loss utility is set to 1 rather than being estimated; thus, the loss-aversion parameter $\lambda$ can be interpreted also as the overall weight on loss utility. For the durationdependence model, the parameter $\tau_{k}$ captures the change over one month in the cost of search.

Estimation. Denote by $m(\xi)$ the vector of moments predicted by the theory as a function of the parameters $\xi$, and by $\hat{m}$ the vector of observed moments. The moments $m(\xi)$ combine the information on average search intensity in minutes from our survey, as well as the administrative information on the hazard rates. For the search intensity, we use the key findings on the within-person search effort path in months 2-6 (Figure VIc) as well as the within-person path around UI expiration (Figure VId). In addition, in order to pin down the level of the pro-

17 For our baseline estimates with $\mathrm{PBD}=12$ and 15 we assume a pre-unemployment wage of 1610 Euro per month. For the $\mathrm{PBD}=8$ and 10 robustness check we assume a wage of 1265 Euro.

18 In the tables we report the speed of adjustment in days, that is, $N^{\star} 30$. 
ductivity of effort across groups $\left(E_{j}\right)$, we also add the average cross-sectional search effort in month 2 and at expiration $(T) .{ }^{19}$ For the hazards, we use the monthly hazard rates from month 2 to month 19 for the PBD group 12 and 15, computed using a standard regression discontinuity design exploiting the age discontinuity in PBD around age 50 (Figure lb).

The estimator chooses the $\hat{\xi}$ to minimize the distance $(m(\xi)-\hat{m})^{\prime} W(m(\xi)-\hat{m})$. As weighting matrix $W$, we weight the hazard moments with the diagonal of the inverse of the estimated variance of the hazard moments; we weight the search effort moments with inverse of the variance-covariance matrix. We upweight the search effort moments by a factor of 10 , to recognize the focus on the novel evidence on search effort, as well as the potential misspecification of the hazard model with respect to the forms of heterogeneity. ${ }^{20}$

To calculate the theoretical moments, we use backward induction. First we numerically compute the steady-state search and value of unemployment. Then we solve for the optimal search and consumption path in each period as a function of the asset level. Finally, we use the initial asset level as a starting value to determine the actual consumption path and search intensity in each period.

Under standard conditions, the minimum-distance estimator using weighting matrix $W$ achieves asymptotic normality, with estimated variance $\left(\hat{G}^{\prime} W \hat{G}\right)^{-1}\left(\hat{G}^{\prime} W \hat{\Lambda} W \hat{G}\right)\left(\hat{G}^{\prime} W \hat{G}\right)^{-1} / N$, where $\hat{G} \equiv N^{-1} \sum_{i=1}^{N} \nabla_{\xi} m_{i}(\hat{\xi})$ and $\hat{\Lambda} \equiv \operatorname{Var}[m(\hat{\xi})]$.

\subsection{Estimates}

Benchmark Estimates. In Table VI, we present estimates for a 3-type standard model in Column 1, two reference-dependent models (with 2 types in Column 2 and with 3 types in Column 3), the duration-dependence model in Column 4 and a model that combines reference dependence and duration dependence in Column 5. We present the estimates for the case of present bias, fixing the long-term monthly discount factor to $\delta=0.995$ (equivalent to an annual 6 percent discount rate). As we document below, the results are qualitatively similar, but with a quantitatively worse fit, if we assume exponential discounting.

The estimates for the standard model indicate a high degree of present bias, a convex effort productivity function and an even more convex cost of effort function; the three types differ substantially in the cost of effort and productivity levels (Table A.27 and Figure A.30). This standard model fits very well the hazard patterns, capturing the decrease and increase up to

\footnotetext{
19 These moments do not affect the fit of the different models, as both standard and referent-dependent models fit them perfectly. They are, however, important to pin down the parameters for the different types, as they document the extent of unobserved heterogeneity in search effort over time.

20 This is similar in spirit to Armstrong/Kolesár (2019).
} 
expiration and decrease thereafter (Figure VIIIC). It also fits reasonably well the flat path of search effort in the initial month (Figure VIIIa), and the increase of search effort up to expiration (Figure VIIIb). It however cannot capture at all the decrease in search effort post expiration (Figure VIIIb), since it predicts a flat search effort after the expiration.

The estimates for the reference-dependent model, focusing first on the 3-type estimate in Column 3, feature a present-bias parameter $\hat{\beta}=0.92$ (s.e. $=0.03$, in the higher range of the estimates in the literature, e.g., Paserman, 2008 and Ganong/Noel, 2019), and loss aversion $\hat{\lambda}=3.73$ (s.e. $=1.01$ ), with a fairly long adaptation period $\widehat{N}=350$ (in days, longer than in the Hungarian context, DellaVigna et al., 2017). As Figure VIIId shows, the model fits very closely the path of the hazard rate, similarly to the fit of the standard model (Figure VIIIC). The model also fits well the flat initial path of search effort in unemployment, given the counterbalancing forces of habituation and increasing option value. The key difference from the standard model is that it fits both the increase in search effort up to expiration, and the decrease thereafter (Figure VIIIb): in the months following the UI exhaustion, the habituation moderates the loss utility due to the cut in benefits, accounting thus for the lower search intensity. The model achieves the fit with moderate impatience, with fairly rapid decumulation over assets (Figure A.31) over the spell. These figures illustrate the importance of the novel evidence on search effort: the standard model and the reference-dependent models would be hardly distinguishable based on the hazard alone.

An important question is whether the better fit of the reference-dependent model (SSE of 103.9 versus 179.2 ) is due to the larger degrees of freedom -13 parameters for the referencedependent model versus 11 for the standard model. Thus, in Column 2 we present the estimates of a reference-dependent model with just 2 types, and thus 10 parameters, one fewer than the standard model. While this model does not fit quite as well as the 3-type referencedependent model in Column 3 (Figure A.33), it does significantly better than the standardmodel, capturing to a good extent the decline post expiration, as well as the other features of the data. This specification achieves the fit for a higher degree of present bias $(\hat{\beta}=0.475)$ and a lower degree of loss aversion $(\hat{\lambda}=1.64)$. This second combination of parameters represents a second basin of attraction for the estimates, as reflected also in the some of the estimates in the robustness table below. Thus, while the evidence clearly supports the referencedependent model over the standard model, our setting is not ideal for precise identification of the degree of loss aversion or present bias, given the difference between Columns 2 and 3 .

Is there then a variant of the standard model that fits as well as the reference-dependent model? As Column 4 shows, a model of duration dependence in search cost-with search getting more costly by about 4 percent for each month in the spell-fits the data even better than the reference-dependent model (SSE of 90.1 versus 103.9). This model captures the hazard patterns (Figure VIIle) and the flat search effort initially (Figure VIIla), but now also 
tracks the increase of search effort up to expiration and decrease thereafter (Figure VIIIb), due to the within-type decrease in search effort post expiration (Figure A.32). While this model is thus an alternative explanation for the search effort data, we caution that we are not aware of evidence regarding the extent of duration dependence, and whether a linear decrease in search costs is an appropriate assumption. For example, if one thought that the duration dependence is driven by changing call back rates over the spell, the audit study in the U.S. of Kroft/Lange/Notowidigdo (2013) points to a decrease in the call back rate for stated unemployment in the cvs of up to 6-8 months, with no further impact beyond that. As Column 4 in Table A.29 shows, if we allow for the cost of effort to grow (or decrease) up to month 8 but to stay constant thereafter, the model does not do much better than the standard model in Column 1 since it cannot reproduce the decrease in search effort post expiration (Figure A.34). In Column 5 we present a model that allows for both reference dependence and duration dependence, achieving an even better quantitative fit than either model, with estimates for the reference-dependence parameters that are close to the ones in Column 2 (see also Figure A.34).

Robustness. In Table A.28 we present a number of alternative specifications, taking as benchmarks the 3-type standard model (Column 1 of Table $\mathrm{VI}$ ) and the 3-type reference-dependent model (Column 3 of Table VI). First, in Column 1 we assume no present bias $(\beta=1)$ and estimate an exponential monthly discount factor $\delta$. The estimates point to similar qualitative patterns as in our benchmark models, but with a worse quantitative fit (see Figure A.33). In Column 2, we estimate both $\beta$ and $\delta$ : we cannot reject a $\delta=0.995$ (as assumed earlier). In Column 3, we show that a reference-dependent model with no heterogeneity (that is, with 1 type) does not fit well (though much better than a standard model with 1 type), not surprisingly given the discrepancy between the initial hazard path and the search effort path. In Column 4, we present estimates from a linear reference-dependent model, with $\eta>0$ but no loss aversion $(\lambda=1)$. Even without loss aversion, reference dependence still has an impact on job search because a high reference point increases differentially the value of employment relative to the value of unemployment, but the fit of this model is not as good as with loss aversion (SSE=122.6 versus 103.9), and in particular it does not fit the decline in search effort after UI expiration very well. In Column 5, we remove the assumption of 0 initial wealth (consistent with the high estimated impatience) and assume assets equal to two months of pre-unemployment income, building on the evidence on assets for US unemployed workers of Ganong/Noel (2019). The qualitative features of the estimates are unchanged, with a slightly worse fit.

In the next three specifications, we vary the moments used. In Column 6, we use the same moments, but we do not upweight the search effort moments, using instead (the diagonal of) the optimal weighting matrix, thus giving much more weight to the hazard moments (estimated on much larger administrative data). The estimates are quite noisy and essentially ignore the search effort moments; hence our choice to upload the search effort moments which are the 
unique contribution of our study. In Column 7, we revert to the benchmark weighting, but we exclude from the estimation the search effort moments for the months past UI expiration. Without these moments, the difference in fit between the standard and the referencedependent model is much smaller, indicating the importance of the expiration moments for identification. Finally, in Column 8 we use the benchmark search effort moments but instead of using the hazard moments for the 12 vs. 15 month PBD, we use the hazards for the 8 versus 10 month PBD. As Figure A.35 also shows, the reference-dependent model has a clearly better fit than the standard model (SSE=137.1 vs. 212.7).

Finally, in Table A.29 we show additional robustness estimates for the standard model. Allowing for heterogeneity in the search cost elasticity $\gamma$ (Column 1) does not improve the fit, unlike in DellaVigna et al. (2017), given that it cannot fit the within-person decrease in search effort post expiration. Next, we present alternative models of worker discouragement. Allowing for an exponential, as opposed to linear, increase in cost of effort (Column 3) yields similar result to our benchmark discouragement model, while allowing for a time trend in productivity, as opposed to in the cost of effort (Column 2), does not fit the data quite as well. As we discussed above, allowing for a time trend in costs of only up to 8 months does not fit the data well (Column 4).

\section{Discussion and Conclusion}

In this paper, we present novel evidence on the search effort of unemployed workers from an SMS-based survey of unemployed workers in Germany. We present three key findings on within-person search effort over the spell. First, the intensity of job search is flat in the initial months of unemployment, from month 2 to month 6 . Second, in the months surrounding $\mathrm{UI}$ expiration search effort first increases up to expiration and then decreases thereafter. Third, we do not find evidence that workers starting a new job at UI expiration had an offer earlier, or stopped searching earlier, as hypothesized under a storable-offer model.

We estimate a model that allows for unobserved heterogeneity in both the cost of search and in the productivity of search effort, using as moments evidence from the survey and on the hazard into employment from matched administrative data. We allow for reference dependence with respect to recent income, to capture a form of backward-looking reference dependence. While both a standard model and a reference-dependent model fit well the path of the hazard and the flat pattern of search effort in the initial months, only the reference-dependent model can explain the increasing and then decreasing pattern of search effort around UI expiration. A modified version of the standard model that allows for worker discouragement 
in the form of increasing costs of search effort over time can also fit the combined evidence, in fact better than the reference-dependent model. However, the pattern of discouragement over time does not appear to be consistent with the evidence from audit studies.

A variety of other models have been proposed to understand observed patterns in job search. A first explanation for the spike at expiration, storable offers, does not find much support in our setting.

A second explanation for the spike at expiration involves recalled workers going back to their jobs. In our context, though, recalls are not common, and we show that the hazard patterns are similar if we exclude recalls.

A third explanation for the search effort patterns is that there may be only a fixed set of jobs to search for and that, after an unemployed worker has gone through them, the worker does not have much scope for additional job search. This could in principle explain why after UI expiration, when presumably workers are search especially intensely, search intensity may decline. Yet, this explanation would predict a temporary decrease in search effort right after UI expiration, not a continuous decrease. Furthermore, if such lumpy nature of search effort were of first-order importance, it likely would manifest itself also in a decrease in search effort over the initial months. We stress that such lumpy search effort patterns may be more of a first-order issue for methods that measure only one type of search effort, such as possibly online postings, than for a measure that aims to capture all margins of search effort, like ours.

Of course, it is possible that a combination of such explanations is at play, in a way that would explain the overall findings. In any case, we hope that the additional evidence on withinperson search intensity will prove useful in providing additional facts to tease alternative models apart. As we stressed in the paper, the fact that we can consider within-person patterns enables us to largely side-steps concerns about unobserved heterogeneity that plays a key role in understanding the patterns in hazard rates from unemployment. 


\section{References}

Allen, Eric J; Dechow, Patricia M; Pope, Devin G; Wu, George (2017): Reference-dependent preferences: Evidence from marathon runners. In: Management Science, Vol. 63, No. 6, p. 1657-1672.

Altmann, Steffen; Falk, Armin; Jäger, Simon; Zimmermann, Florian (2018): Learning about Job Search: A Field Experiment with Job Seekers in Germany. In: Journal of Public Economics, Vol. 164, p. 33-49, URL http://www.voxeu.org/article/learning-about-job-search-tackling-long-term-unemployment.

Armstrong, Timothy; Kolesár, Michal (2019): Sensitivity analysis using approximate moment condition models. In: .

Arni, Patrick; Schiprowski, Amelie (2019): Job search requirements, effort provision and labor market outcomes. In: Journal of Public Economics, Vol. 169, p. 65 - 88, URL http://www.sciencedirect.com/science/article/pii/S0047272718301725.

Augenblick, Ned; Rabin, Matthew (2019): An Experiment on Time Preference and Misprediction in Unpleasant Tasks. In: The Review of Economic Studies, Vol. 86, No. 3, p. 941-975, URL https://doi.org/10.1093/restud/rdy019.

Ballivian, Amparo; Azevedo, J; Durbin, Will; Rios, J; Godoy, J; Borisova, C (2015): Using mobile phones for high-frequency data collection. In: Mobile Research Methods, p. 21.

Barberis, Nicholas (2018): Psychology-based Models of Asset Prices and Trading Volume. In: Bernheim, Douglas; DellaVigna, Stefano; Laibson, David (Eds.) Handbook of Behavioral Economics, North Holland.

Barseghyan, Levon; Molinari, Francesca; O’Donoghue, Ted; Teitelbaum, Joshua C (2013): The nature of risk preferences: Evidence from insurance choices. In: American Economic Review, Vol. 103, No. 6, p. 2499-2529.

Belot, Michele; Kircher, Philipp; Muller, Paul (2019): Providing advice to jobseekers at low cost: An experimental study on online advice. In: The Review of Economic Studies, Vol. 86, No. 4, p. 1411-1447.

Berkouwer, Susanna B; Dean, Joshua T (2019): Inattention and credit constraints in energy efficiency adoption: Evidence from Kenya. In: .

Boone, Jan; van Ours, Jan C (2012): Why is there a spike in the job finding rate at benefit exhaustion? In: De Economist, Vol. 160, No. 4, p. 413-438.

Bordalo, Pedro; Gennaioli, Nicola; Shleifer, Andrei (2020): Memory, Attention, and Choice. In: Quarterly Journal of Economics, Vol. 135, p. 1399-1442. 
Caliendo, Marco; Tatsiramos, Konstantinos; Uhlendorff, Arne (2013): Benefit duration, unemployment duration and job match quality: a regression-discontinuity approach. In: Journal of Applied Econometrics, Vol. 28, No. 4, p. 604-627.

Card, David; Chetty, Raj; Weber, Andrea (2007): Cash-on-hand and competing models of intertemporal behavior: New evidence from the labor market. In: The Quarterly Journal of Economics, Vol. 122, No. 4, p. 1511-1560.

DellaVigna, Stefano (2009): Psychology and Economics: Evidence from the Field. In: Journal of Economic Literature, Vol. 47, No. 2, p. 315-372.

DellaVigna, Stefano; Lindner, Attila; Reizer, Balázs; Schmieder, Johannes F (2017): Referencedependent job search: Evidence from Hungary. In: The Quarterly Journal of Economics, Vol. 132, No. 4, p. 1969-2018.

DellaVigna, Stefano; Pope, Devin (2018): Predicting experimental results: who knows what? In: Journal of Political Economy, Vol. 126, No. 6, p. 2410-2456.

DellaVigna, Stefano; Pope, Devin; Vivalt, Eva (2019): Predict science to improve science. In: Science, Vol. 366, No. 6464, p. 428-429, URL https://science.sciencemag.org/content/366/6464/428.

Dlugosz, Stephan; Wilke, Ralf A; Stephan, Gesine (2014): Fixing the leak: unemployment incidence before and after a major reform of unemployment benefits in Germany. In: German Economic Review, Vol. 15, No. 3, p. 329-352.

Domenech, Gerard; Vannutelli, Silvia (2019): Bringing Them In or Pushing Them Out? The Impact of Benefit Cuts for Long-Term Unemployed in Times of Crisis. In: mimeo.

Faberman, R. Jason; Kudlyak, Marianna (2019): The Intensity of Job Search and Search Duration. In: American Economic Journal: Macroeconomics, Vol. 11, No. 3, p. 327-57, URL http://www.aeaweb.org/articles?id=10.1257/mac.20170315.

Faberman, R. Jason; Mueller, Andreas I; Şahin, Ayşegül; Topa, Giorgio (2017): Job Search Behavior among the Employed and Non-Employed. Working Paper 23731, National Bureau of Economic Research, URL http://www.nber.org/papers/w23731.

Fitzenberger, Bernd; Wilke, Ralf A (2010): Unemployment durations in West Germany before and after the reform of the unemployment compensation system during the 1980s. In: German Economic Review, Vol. 11, No. 3, p. 336-366.

Fujita, Shigeru; Moscarini, Giuseppe (2017): Recall and unemployment. In: American Economic Review, Vol. 107, No. 12, p. 3875-3916.

Ganong, Peter; Noel, Pascal (2019): Consumer spending during unemployment: Positive and normative implications. In: American Economic Review, Vol. 109, No. 7, p. 2383-2424. 
Gautier, Pieter A.; Moraga-González, Josè L.; Wolthoff, Ronald P. (2016): Search costs and efficiency: Do unemployed workers search enough? In: European Economic Review, Vol. 84, p. 123-139, URL https://www.sciencedirect.com/science/article/pii/S0014292115000501, european Labor Market Issues.

Hoogeveen, Johannes; Croke, Kevin; Dabalen, Andrew; Demombynes, Gabriel; Giugale, Marcelo (2014): Collecting high frequency panel data in Africa using mobile phone interviews. In: Canadian Journal of Development Studies/Revue canadienne d'études du développement, Vol. 35, No. 1, p. 186-207.

Johansen, Bendt; Wedderkopp, Niels (2010): Comparison between data obtained through real-time data capture by SMS and a retrospective telephone interview. In: Chiropractic \& osteopathy, Vol. 18, No. 1, p. 10.

Johnston, Andrew C; Mas, Alexandre (2018): Potential unemployment insurance duration and labor supply: The individual and market-level response to a benefit cut. In: Journal of Political Economy, Vol. 126, No. 6, p. 2480-2522.

Katz, Lawrence F. (1986): Layoffs, Recall and the Duration of Unemployment. Working Paper 1825, National Bureau of Economic Research, URL http://www.nber.org/papers/w1825.

Katz, Lawrence F; Meyer, Bruce D (1990): Unemployment insurance, recall expectations, and unemployment outcomes. In: The Quarterly Journal of Economics, Vol. 105, No. 4, p. $973-$ 1002.

Kolsrud, Jonas; Landais, Camille; Nilsson, Peter; Spinnewijn, Johannes (2018): The optimal timing of unemployment benefits: Theory and evidence from sweden. In: American Economic Review, Vol. 108, No. 4-5, p. 985-1033.

Kőszegi, Botond; Rabin, Matthew (2006): A model of reference-dependent preferences. In: The Quarterly Journal of Economics, Vol. 121, No. 4, p. 1133-1165.

Kroft, Kory; Lange, Fabian; Notowidigdo, Matthew J (2013): Duration dependence and labor market conditions: Evidence from a field experiment. In: The Quarterly Journal of Economics, Vol. 128, No. 3, p. 1123-1167.

Krueger, Alan B; Mueller, Andreas (2011): Job search, emotional well-being, and job finding in a period of mass unemployment: Evidence from high frequency longitudinal data. In: Brookings Papers on Economic Activity, p. 1-81.

Krueger, Alan B; Mueller, Andreas (2010): Job search and unemployment insurance: New evidence from time use data. In: Journal of Public Economics, Vol. 94, No. 3-4, p. 298-307.

Kuntsche, Emmanuel; Robert, Benjamin (2009): Short Message Service (SMS) Technology in Alcohol Research - A Feasibility Study. In: Alcohol and Alcoholism, Vol. 44, No. 4, p. 423428, URL https://doi.org/10.1093/alcalc/agp033. 
Lalive, Rafael; Landais, Camille; Zweimüller, Josef (2015): Market externalities of large unemployment insurance extension programs. In: The American Economic Review, p. 35643596.

Le Barbanchon, Thomas; Rathelot, Roland; Roulet, Alexandra (2019): Unemployment insurance and reservation wages: Evidence from administrative data. In: Journal of Public Economics, Vol. 171, p. 1 - 17, URL http://www.sciencedirect.com/science/article/pii/S0047272717300671.

Leung, Pauline; O'Leary, Christopher (2019): Unemployment Insurance and Means-Tested Program Interactions: Evidence from Administrative Data. In: American Economic Journal: Economic Policy.

Lichter, Andreas; Schiprowski, Amelie (2020): Benefit Duration, Job Search Behavior and ReEmployment. mimeo, IZA.

Marinescu, Ioana; Skandalis, Daphné (2021): Unemployment Insurance and Job Search Behavior. In: The Quarterly Journal of Economics, Vol. 136, No. 2, p. 887-931, URL https://doi.org/10.1093/qje/qjaa037.

Meyer, Bruce D (1990): Unemployment Insurance and Unemployment Spells. In: Econometrica, Vol. 58, No. 4, p. 757-782.

Moffitt, Robert (1985): Unemployment insurance and the distribution of unemployment spells. In: Journal of Econometrics, Vol. 28, No. 1, p. 85-101.

Mueller, Andreas I; Spinnewijn, Johannes; Topa, Giorgio (2021): Job Seekers' Perceptions and Employment Prospects: Heterogeneity, Duration Dependence and Bias. Tech. Rep. 1.

Nekoei, Arash; Weber, Andrea (2017): Does extending unemployment benefits improve job quality? In: American Economic Review, Vol. 107, No. 2, p. 527-61.

Nekoei, Arash; Weber, Andrea (2015): Recall expectations and duration dependence. In: American Economic Review, Vol. 105, No. 5, p. 142-46.

O'Donoghue, Ted; Sprenger, Charles (2018): Reference-dependent preferences. In: Handbook of Behavioral Economics: Applications and Foundations 1, Vol. 1, Elsevier, p. 1-77.

Paserman, M Daniele (2008): Job search and hyperbolic discounting: Structural estimation and policy evaluation. In: The Economic Journal, Vol. 118, No. 531, p. 1418-1452.

Potter, Tristan (2021): Learning and job search dynamics during the Great Recession. In: Journal of Monetary Economics, Vol. 117, p. 706-722, URL https://www.sciencedirect.com/science/article/pii/S0304393220300532.

Rees-Jones, Alex (2018): Quantifying loss-averse tax manipulation. In: The Review of Economic Studies, Vol. 85, No. 2, p. 1251-1278. 
Rothstein, Jesse (2011): Unemployment Insurance and Job Search in the Great Recession. In: Brookings Papers on Economic Activity, Vol. 2011, No. 2, p. 143-213.

Schmieder, Johannes F; Trenkle, Simon (2020): Disincentive effects of unemployment benefits and the role of caseworkers. In: Journal of Public Economics, Vol. 182, p. 104 096, URL http://www.sciencedirect.com/science/article/pii/S0047272719301574.

Schmieder, Johannes F; von Wachter, Till (2016): The effects of unemployment insurance benefits: New evidence and interpretation. In: Annual Review of Economics, Vol. 8, p. 547581.

Schmieder, Johannes F; von Wachter, Till; Bender, Stefan (2016): The effect of unemployment benefits and nonemployment durations on wages. In: American Economic Review, Vol. 106, No. 3, p. 739-77.

Schmieder, Johannes F; von Wachter, Till; Bender, Stefan (2012): The effects of extended unemployment insurance over the business cycle: Evidence from regression discontinuity estimates over 20 years. In: The Quarterly Journal of Economics, Vol. 127, No. 2, p. 701752.

Sydnor, Justin (2010): (Over) insuring modest risks. In: American Economic Journal: Applied Economics, Vol. 2, No. 4, p. 177-99.

Thakral, Neil; Tô, Linh T. (forthcoming): Daily labor supply and adaptive reference points. In: American Economic Review.

van den Berg, Gerard J (1990): Nonstationarity in job search theory. In: The Review of Economic Studies, Vol. 57, No. 2, p. 255-277. 


\section{Appendix}

Figures 


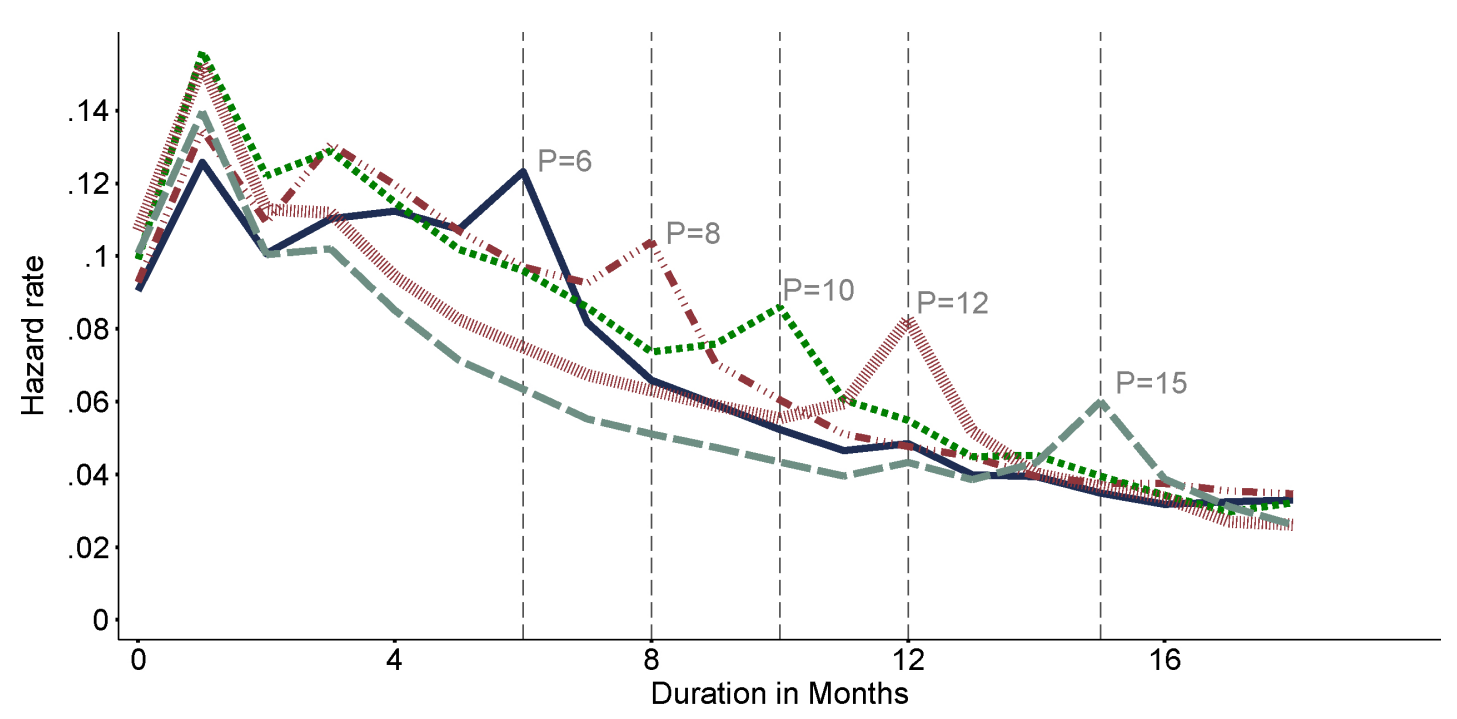

(a) All Eligibility Categories

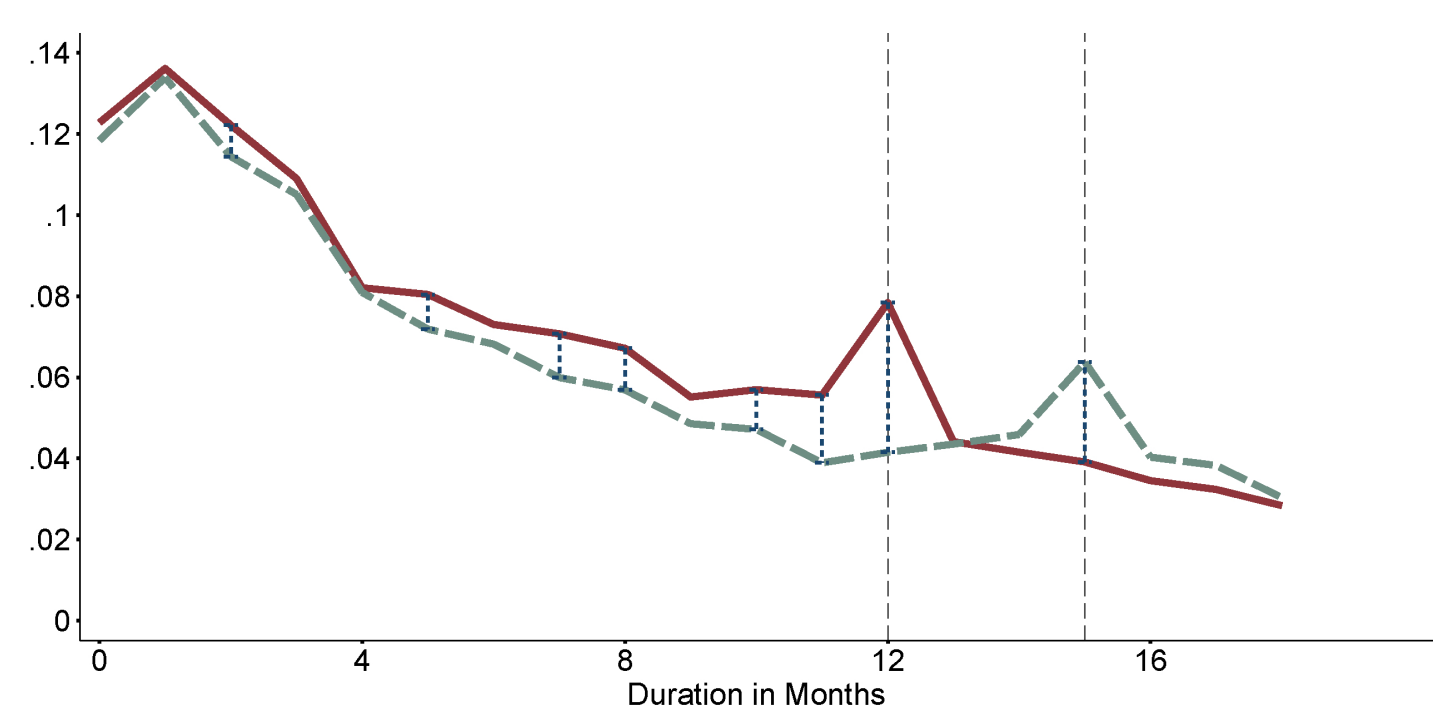

(b) Regression Discontinuity at Age 50

Notes: This figure shows reemployment hazards by PBD groups based on administrative data for individuals entering UI between January 2017 and June 2019. Panel (a) shows hazard rates for all 5 PBD-groups, whereas figure (b) provides RD-estimates of the 12 vs. 15 month eligibility group around the discontinuity at age 50 . The sample consists of individuals aged between 28 and 60 at time of UI entry and have exactly 6, 8, 10, 12 or 15 months of $P B D$ at $U I$ entry. For $P B D=12$ and $P B D=15$, we additionally restrict to age between 45 and 55 at time of UI entry and on qualifying for long UI eligibility based on working history. We also restrict to immediate UI takeup after job-loss ( $<2$ days). Numbers of observations for panel a) are for $\mathrm{P}=6$ : 68105 , for $\mathrm{P}=8: 48773$, for $\mathrm{P}=10$ : 37396, for $P=12$ : 148991 and for $P=15: 143182$. For panel $b$ ) the numbers of observations are 55045 for $P=12$ and 59460 for $P=15$.

Source: Own calculations. CIAB 
Figure 2: Survey Design
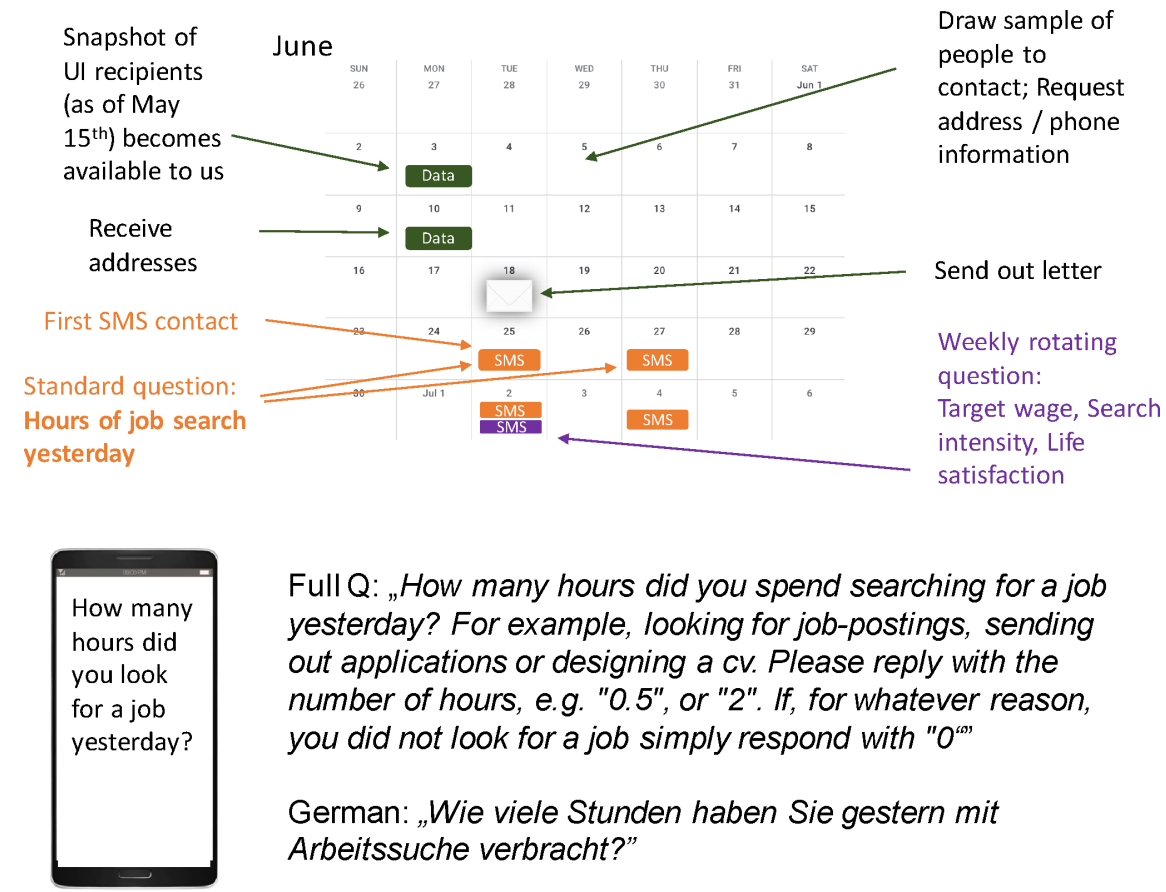

Full Q: „How many hours did you spend searching for a job yesterday? For example, looking for job-postings, sending out applications or designing a cv. Please reply with the number of hours, e.g. "0.5", or "2". If, for whatever reason, you did not look for a job simply respond with "O"

German: „Wie viele Stunden haben Sie gestern mit Arbeitssuche verbracht?"

(a) Timing of Sampling and Survey Design

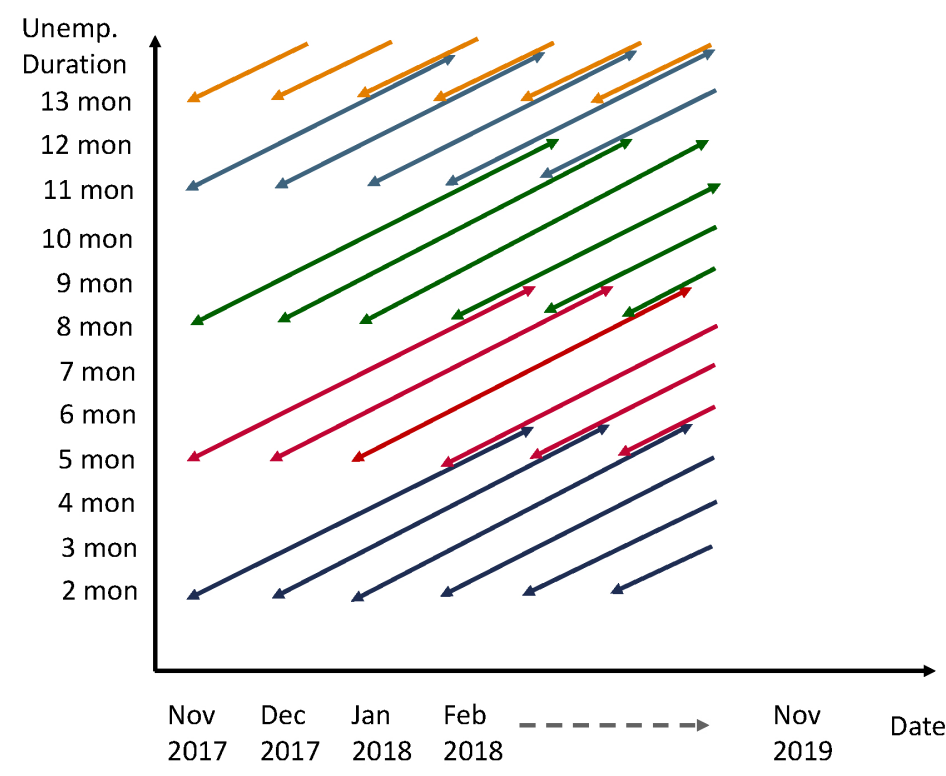

(b) Overlapping Panel Design for $\mathrm{P}=12$ Group

Notes: This figure illustrates (a) the overlapping cohort structure by wave, and (b) timing of data retrieval, send out of letter and first SMS contact.

Source: Own calculations. CIAB 
Figure 3: Distribution and Time Series of Job Search Measure

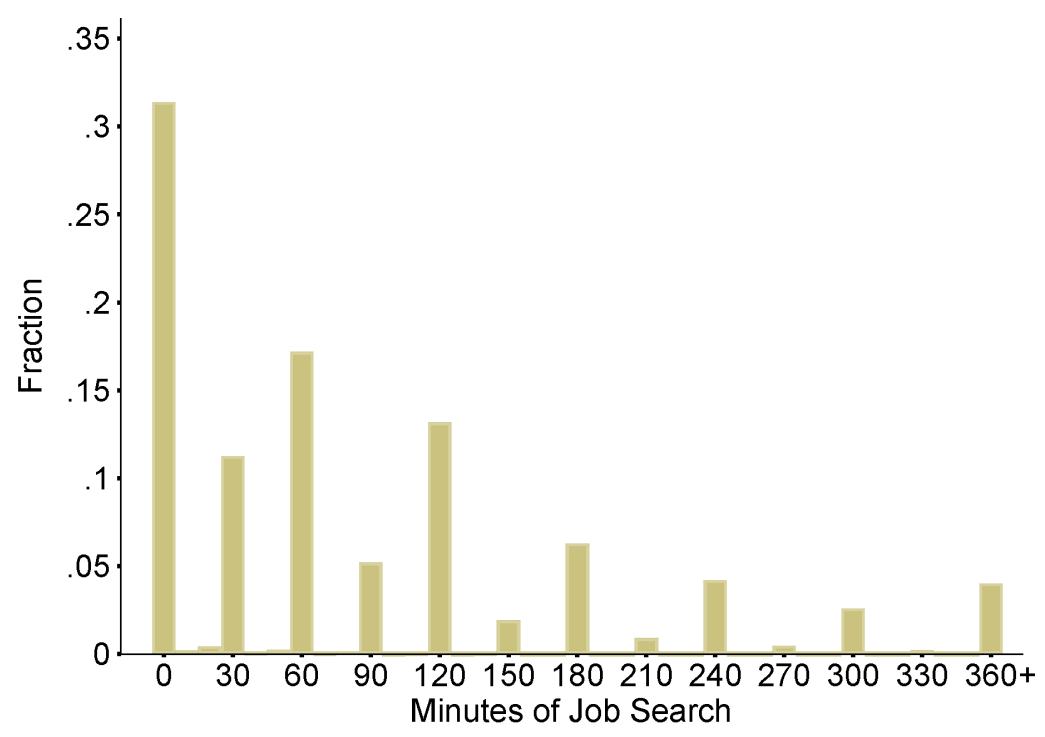

(a) Histogram of Job Search Responses, $\mathrm{N}=115,207$

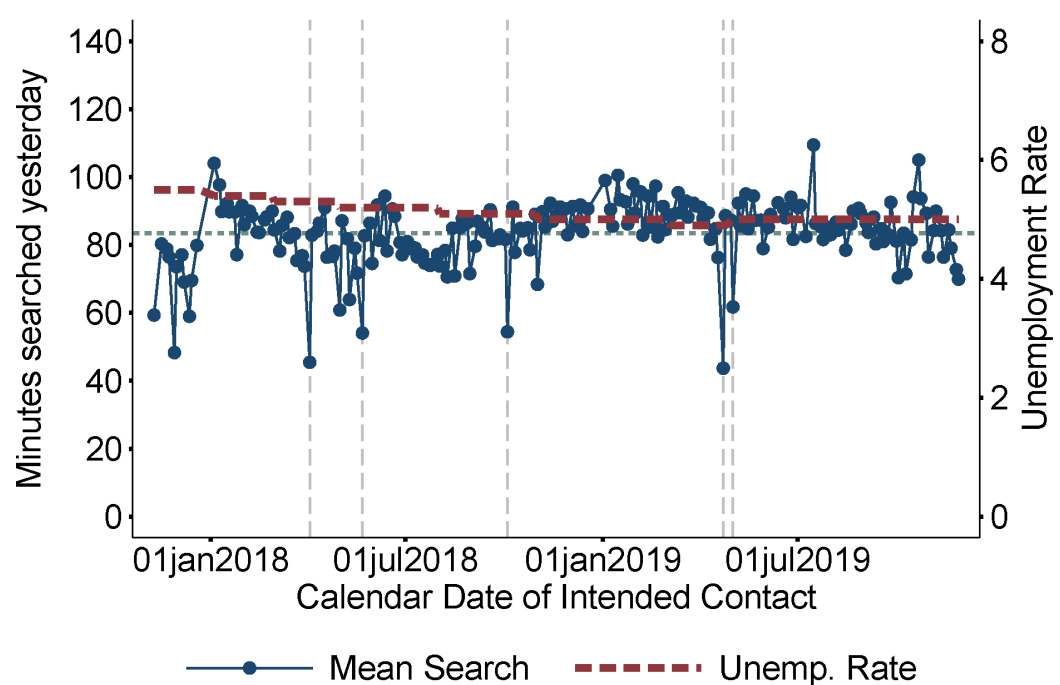

(b) Time Series of Job Search and Unemployment Rates

Notes: Panel (a) shows a histogram for job-search for all responses for individuals who still report being nonemployed. We drop responses above 15 hours and censor responses to 6 hours. Panel (b) shows time series of mean daily search (of nonemployed job searchers) for days with at least 20 valid responses. If a person responds to a question the following day, we still code the response for the day that we originally asked about (for example Monday if the question was sent out on Tuesday but answered on Wednesday). The horizontal dashed line indicates the mean job search over the whole period, the vertical dashed lines indicate days of federal public holidays. The red dashed line shows the seasonally adjusted monthly unemployment rate.

Source: Own calculations. CIAB 
Figure 4: Validation of Search Effort Measure

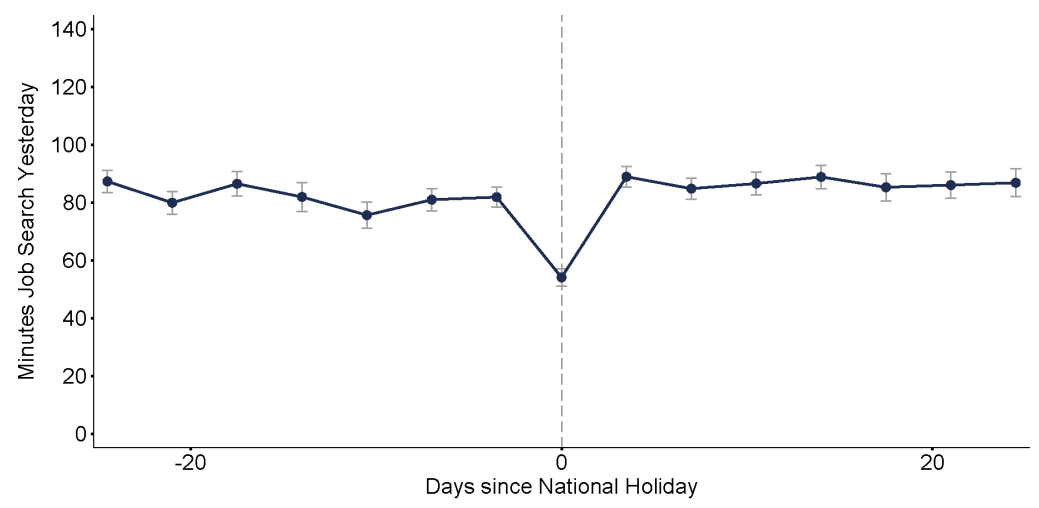

(a) Search Effort Around National Holidays

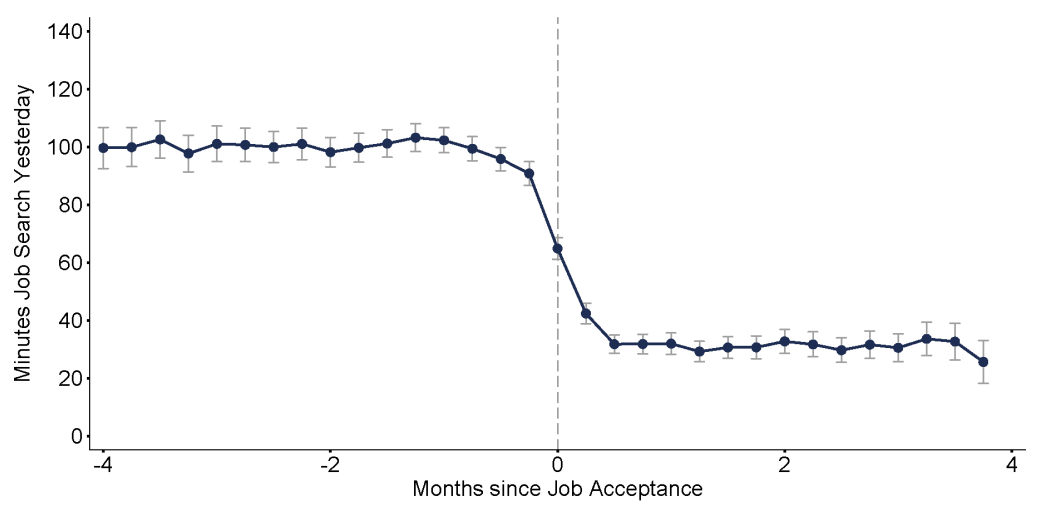

(b) Search Effort Around Job Finding

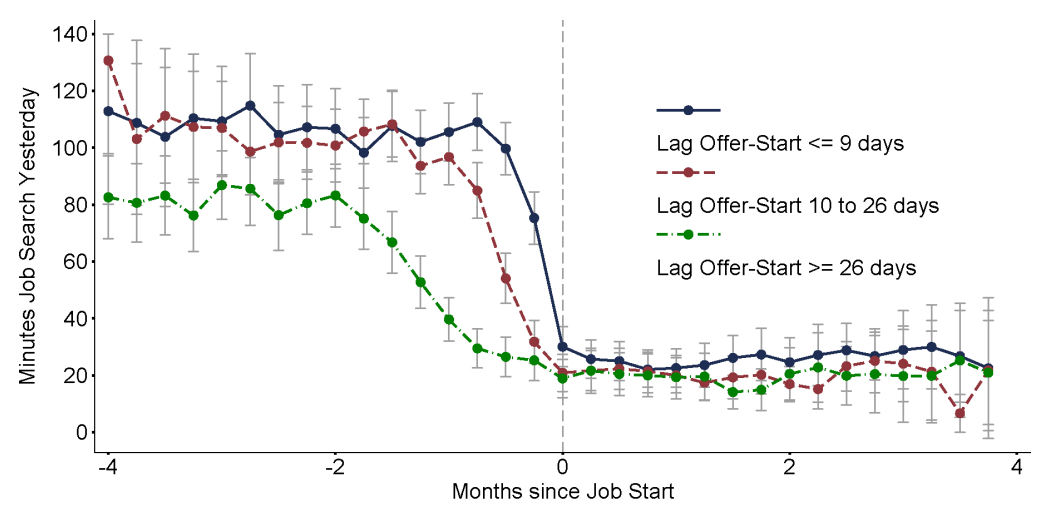

(c) Search Effort Around Job Start, by time since Acceptance

Notes: This figure shows mean job search effort for individuals around different events. Event dates are normalized to zero. Figure (a) restricts to nonemployed individuals only. In figure (a) the distance between two survey dates (Tuesday $->$ Thursday and Thursday $->$ Tuesday) is standardized to 3.5 days for the ease of comparison. Figure (b) shows job search before and after the job found date. The job found date combines information from survey and admin data (see appendix D for details). Figure (c) shows job search before and after job start, split by the gap between job offer and job start date.

Source: Own calculations. OIAB 


\section{Figure 5: Search Effort (Minutes of Job-Search Yesterday) over the Unemployment Spell by Survey Cohort}

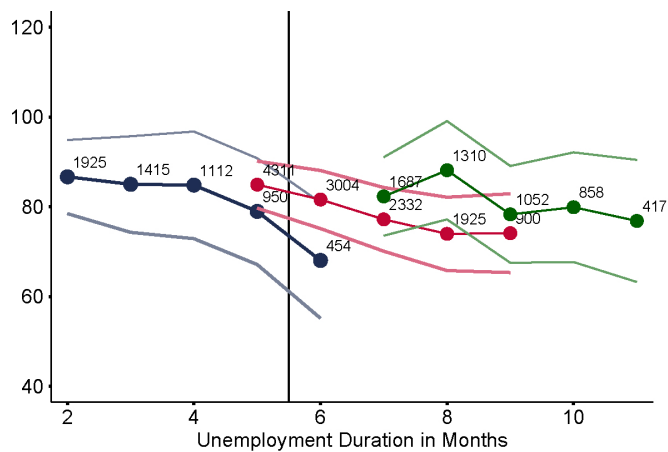

(a) $\mathrm{P}=6$ Months Group

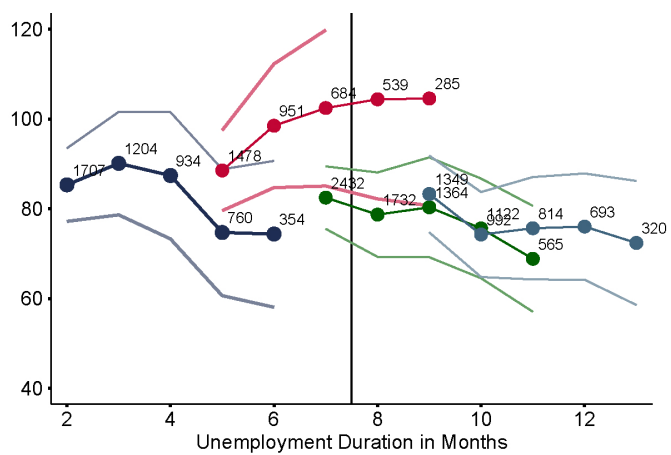

(b) $P=8$ Months Group

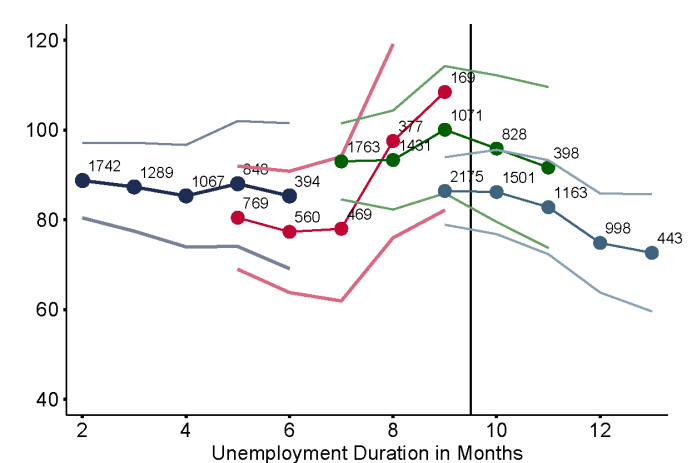

(c) $P=10$ Months Group

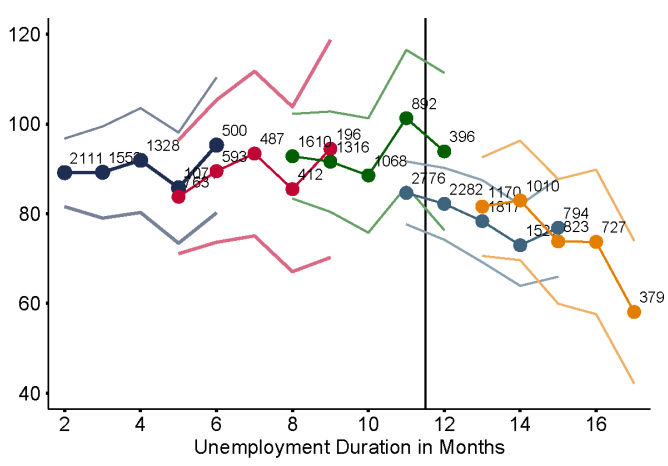

(d) $P=12$ Months Group

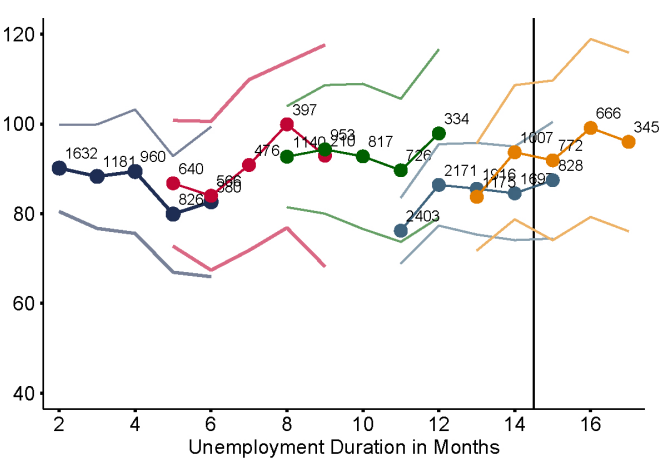

(e) $P=15$ Months Group

Notes: This figure shows cohort plots for $\mathrm{P}=6$ to $\mathrm{P}=15$ months. $95 \% \mathrm{Cl}$ (SE clustered on individual level) are displayed as outer lines (values above 120 and below 40 are censored for the ease of exposition). Numbers at a dot refer to the numbers of observations on which the dot is based. A cohort is defined as the duration in months on UI at time of first contact. It contains the months 2,3,5,8,11,13. Values that are -due to slight differences in definition of cohorts in earlier waves- outside those range are increased by one month such that they fit in the listed month range. One dot represents observations from 4 weeks. Since responses are restricted to the regular survey duration (up to 18 weeks), the last dot of each cohort contains only observations from two weeks.

Source: Own calculations. CIAB 
Figure 6: Search Effort Throughout the Unemployment Spell
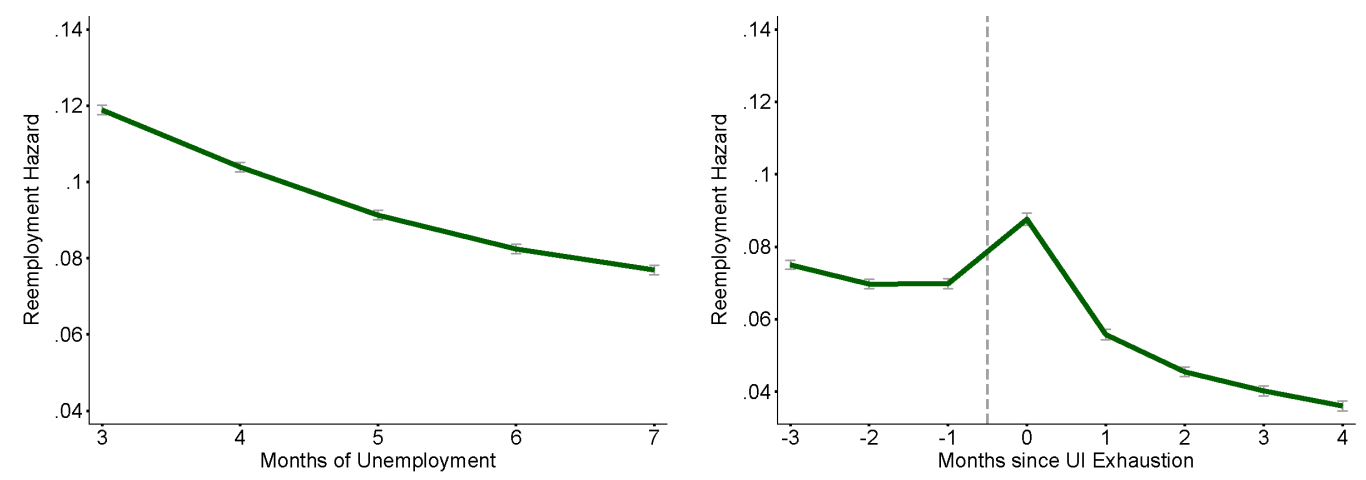

(a) Initial Evolution of Hazard Rate, $\mathrm{N}=344,337$

(b) Hazard Rate around UI Exhaustion, $\mathrm{N}=163,851$
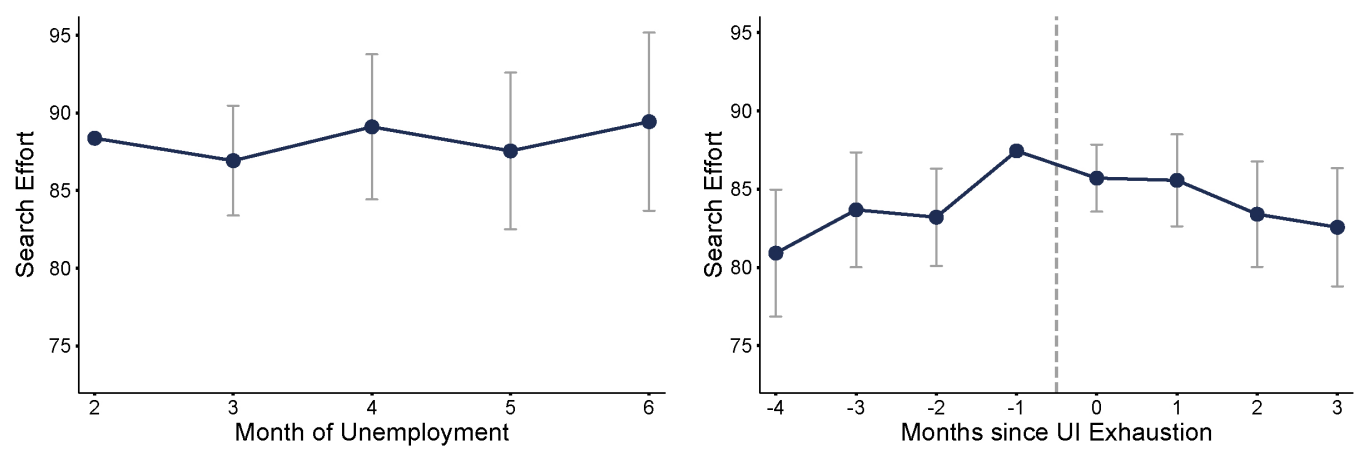

(c) Initial Evolution of Search Effort ( $\mathrm{N}$ ind. $=1844$, (d) Search Effort around UI Exhaustion (N ind. = N obs. $=28148$ )

$5110, \mathrm{~N}$ obs. $=84590)$
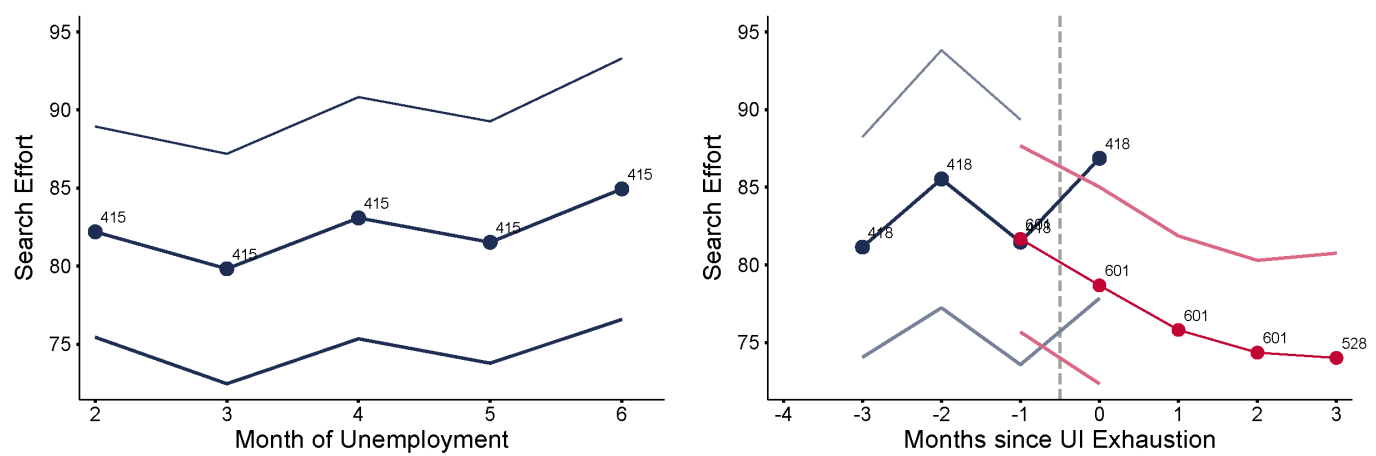

(e) Initial Evolution of Search Effort - Full Partici- (f) Search Effort around UI Exhaustion - Full Particpants and Constant Cohort ipants and Constant Cohort

Notes: The figure shows mean job search over the initial spell of unemployment (up to 6 months) and around UI-exhaustion (between -4 and +3 months around $\mathrm{UI}$ exhaustion) controlling for individual, week-date and calender-month fixed effects and compares it to reemployment hazard in those months. For the initial evolution of search effort only individuals with $P \geq 8$ are included. Standard errors are clustered on the person level. Hazard rates are based on the same administrative data as in figure (1) but pooled over different P-groups. To match the characteristics of the surveyed individuals, each P-group is weighted with the number of individuals that participate in the survey at the beginning of the UI spell (month 2) in that particular group. Figure (e) and (f) show cohort plots pooling different eligibility durations and restricting to individuals that participate fully in the survey while also being nonemployed.

Source: Own calculations. CIAB 
Figure 7: Evidence about Storable Offer Model

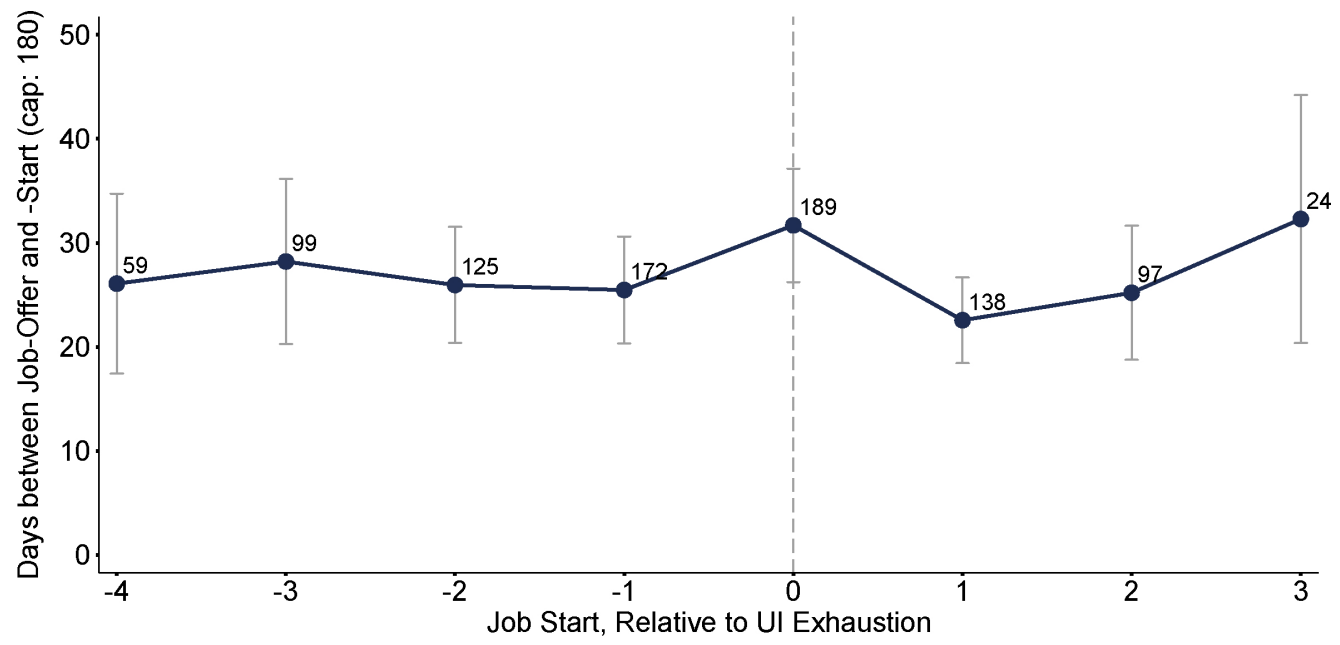

(a) Mean Duration between Job-Offer and Job-Found by Date of UI Exhaustion

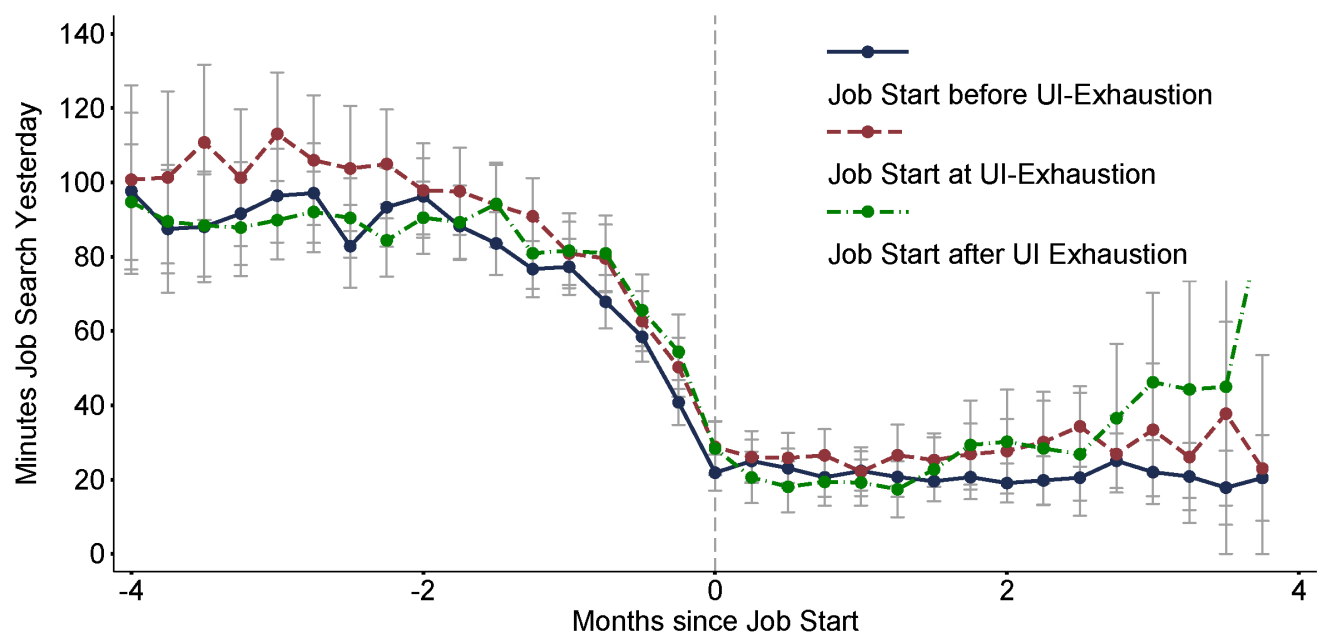

(b) Job Search Effort by Job Found and Date of UI Exhaustion

Notes: Panel (a) shows the duration in days between job-offer and job start by the month of the job start relative to UI exhaustion. Panel (b) shows reported job search intensity around job start by whether individuals start their job around UI exhaustion (+/- one month around UI exhaustion) or at other points of their unemployment spell.

Source: Own calculations. CIAB 
Figure 8: Empirical Moments and Fit for Standard Model, Reference-Dependent Model, and Duration-Dependence Model

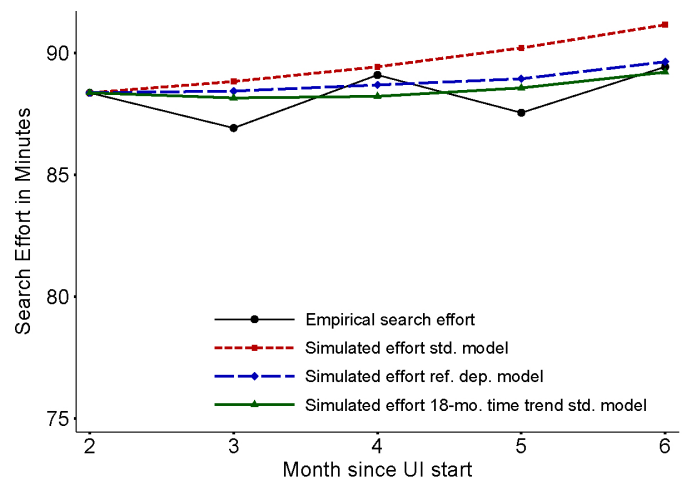

(a) Search effort at beginning of UI spell

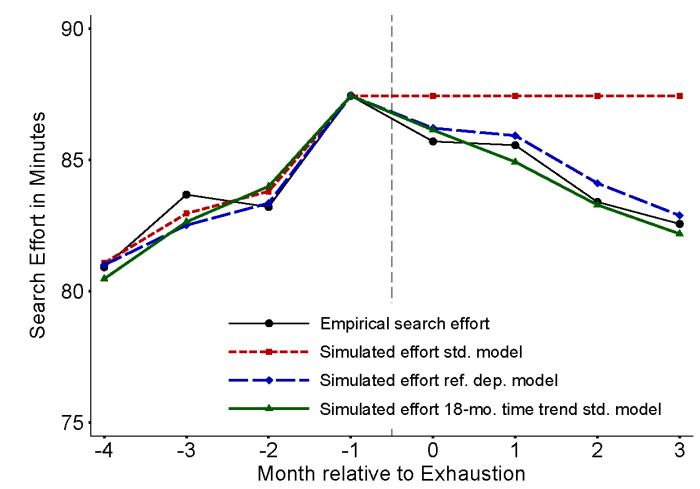

(b) Search effort around UI exhaustion

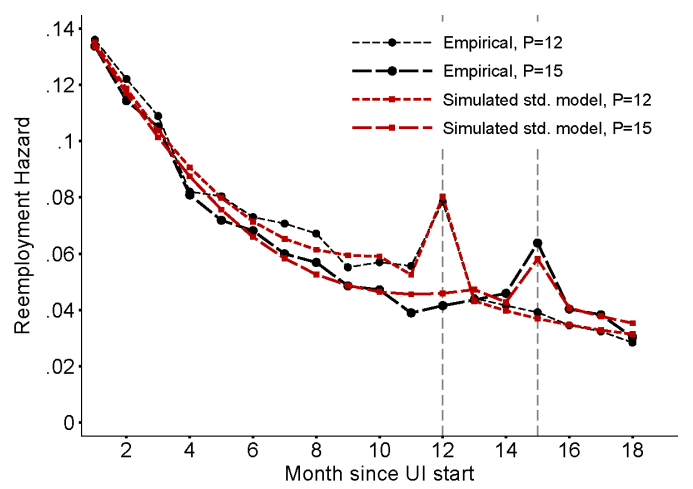

(c) Hazard rate for standard model

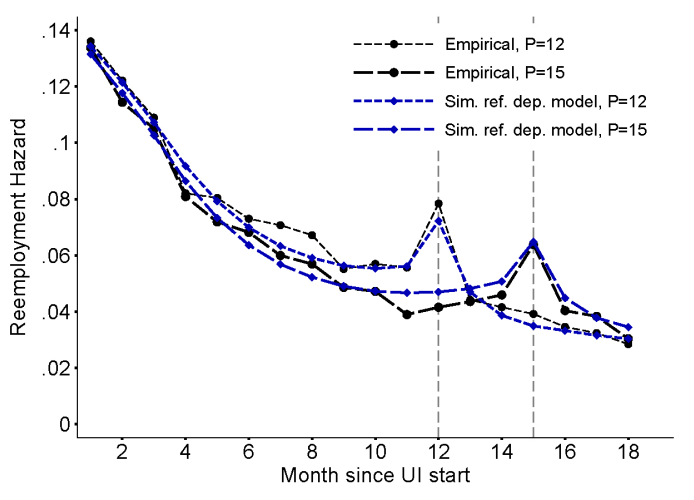

(d) Hazard rate for ref.-dep. model

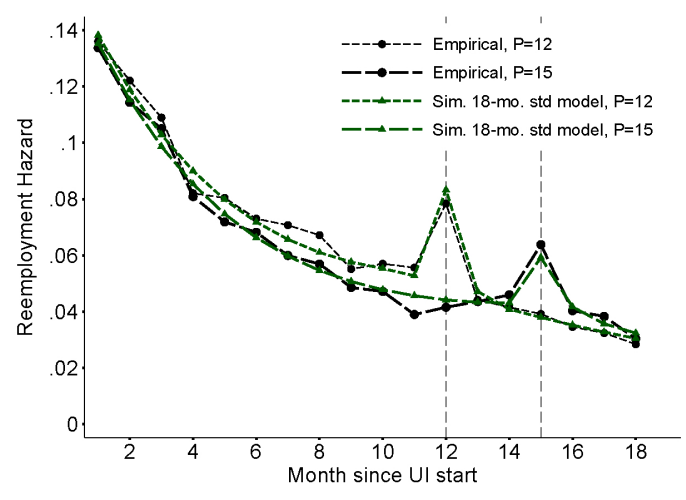

(e) Hazard rate for duration-dependence model

Notes: The figure shows the empirical moments that we use in the structural estimation and the predicted moments from the estimated standard model, the reference-dependent model, as well as the duration-dependence model i.e. the standard model with an 18 month time trend in $\mathrm{K}$.

model, as well as the duration-d 


\section{Tables}


Table 1: Summary Table

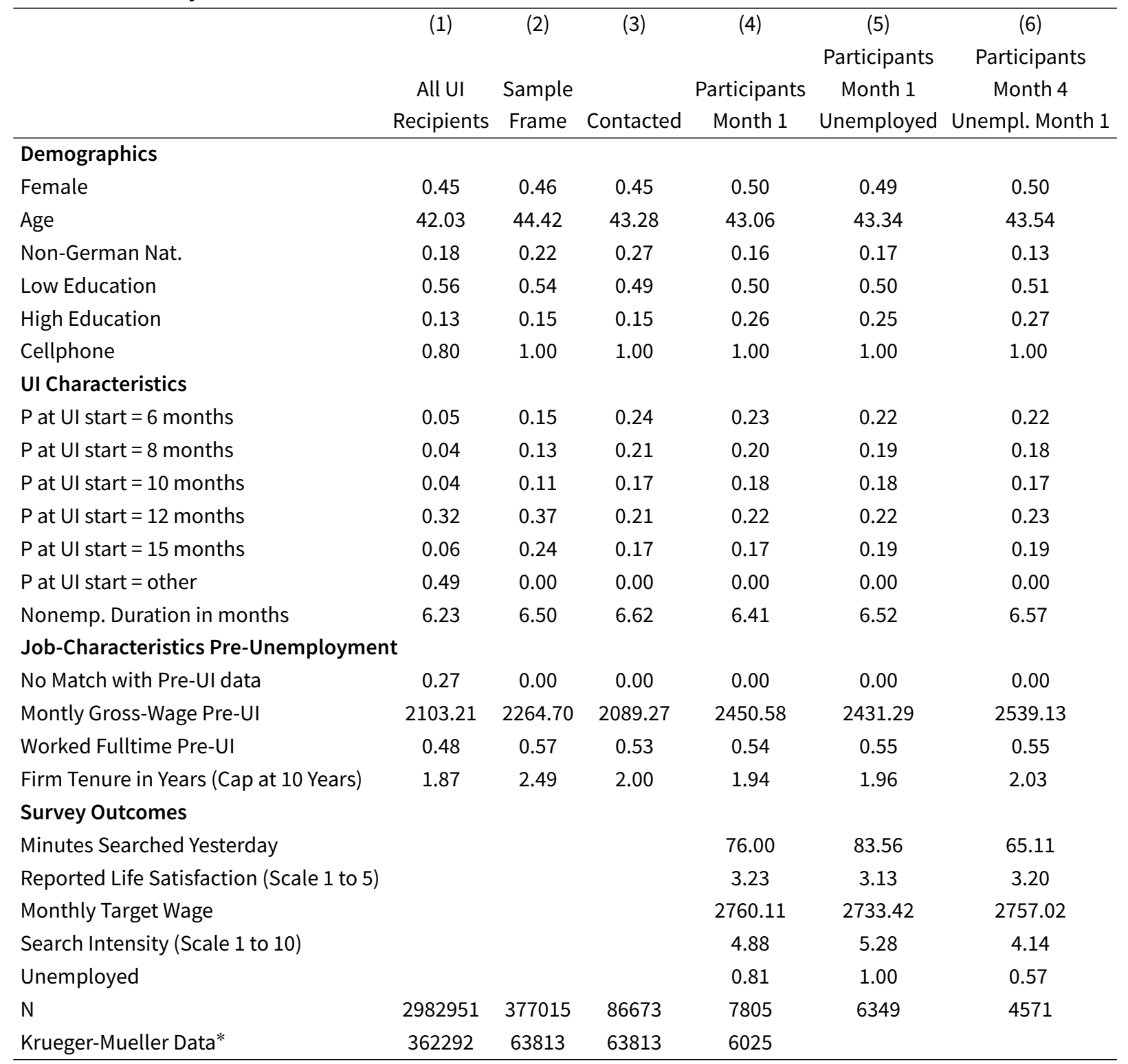

Notes: This table summarizes characteristics of the stock of UI recipients at different stages of the sampling process. Column (1) shows all UI recipients for all waves the survey was running. Column (2) shows all individuals that fulfill the basic sampling requirements. Column (3) represent the actually contacted individuals, which are a stratified random sample based on PxD cells. Column (4) contains all individuals that participated initially in the survey, column (5) shows participants that were also unemployed and column (6) shows individuals that were initially unemployed and still participated in the last month of the survey. Survey outcomes (except job search) contain first (columns 4 and 5) and last (column 6) observation of each participant.

${ }^{*}$ Numbers retrieved from tables and text in Krueger and Mueller (2011).

Source: Own calculations. CIAB 
Table 2: Tests for Survey Response Bias

(2)

German SMS Data

Panel A: Test for Survey Response Bias in SMS and KM-Data

First Survey Response

Months Unemployed

Adj. $\mathrm{R}^{2}$

Mean Job Search

$\mathrm{N}$ Individuals

$\mathrm{N}$

p-Val. of Difference Col. (2) and (3)/(5) and (6)

Individual Controls

Panel B: Direct Estimate for Survey Response Bias

Survey Duration in Months

Adj. $R^{2}$

Mean Dep. Var

$\mathrm{N}$ Individuals

N

P-Group x Unemp. Dur. FE

Time (running week) FE

Individual Controls

\begin{tabular}{|c|c|c|c|c|c|}
\hline \multicolumn{2}{|c|}{ First Survey Response } & All Responses & \multicolumn{2}{|c|}{ First Survey Response } & All Responses \\
\hline Between & Between w/ controls & Within & Between & Between w/ controls & Within \\
\hline$-0.688^{* *}$ & -0.458 & -0.202 & $1.099 * *$ & 0.667 & $-10.948^{* * *}$ \\
\hline [0.324] & [0.349] & [0.310] & {$[0.540]$} & {$[0.498]$} & [1.124] \\
\hline 0.00 & 0.03 & 0.49 & 0.01 & 0.06 & 0.61 \\
\hline 81.08 & 81.08 & 84.85 & 117.24 & 116.82 & 69.90 \\
\hline 6244 & 6244 & 6244 & 3285 & 3231 & 4523 \\
\hline \multirow[t]{4}{*}{6244} & 6244 & 113708 & 3285 & 3231 & 21598 \\
\hline & & 0.551 & & & 0.000 \\
\hline & $\mathrm{X}$ & & & $\mathrm{X}$ & \\
\hline & & $x$ & & & $X$ \\
\hline \multicolumn{6}{|l|}{ ias } \\
\hline 0.454 & 0.387 & 0.212 & & & \\
\hline [0.684] & {$[0.727]$} & {$[0.700]$} & & & \\
\hline 0.003 & 0.008 & 0.043 & & & \\
\hline 85.016 & 85.016 & 85.016 & & & \\
\hline 6349 & 6349 & 6349 & & & \\
\hline 115204 & 115204 & 115204 & & & \\
\hline \multirow[t]{3}{*}{$x$} & $\mathrm{X}$ & $\mathrm{X}$ & & & \\
\hline & $x$ & $x$ & & & \\
\hline & & $\mathrm{X}$ & & & \\
\hline
\end{tabular}

Notes: Panel A performs the test for survey response bias as outlined in Krueger-Mueller (2011), applied to the German SMS-data (columns (1) to (3)) as well as to the original K\&M data (columns (4)-(6)). In column (1)-(2) and (4)-(5) of Panel A, we only use the first response to the job-search question, conditional on that this response happens within the first week after survey start. Unemployment duration is the difference between UI-entry and the day of the interview (scaled to months). For the K\&M data we restrict to weekday responses at time of nonemployment and an age range between 20 and 65 years. Standard errors clustered at the level of individuals. Panel B performs a refined survey test that makes use of the repeated wave structure in the German SMS data. Significance levels: ${ }^{*} p<0.1,{ }^{\star \star} p<0.05,{ }^{* \star} p<0.01$

Source: Own calculations. CIAB 
Table 3: Search Effort Since Start of UI Spell

\begin{tabular}{lcccc}
\hline & $(1)$ & $(2)$ & $(3)$ & $(4)$ \\
\hline [2, 3] months (omitted category) & 0.00 & 0.00 & 0.00 & 0.00 \\
& {$[]$.} & {$[]$.} & {$[]$.} & {$[]$.} \\
on UI since [3, 4] months & 0.37 & -0.84 & -1.42 & -1.45 \\
& {$[2.02]$} & {$[1.97]$} & {$[1.77]$} & {$[1.80]$} \\
on UI since [4, 5] months & 0.35 & -1.33 & 0.19 & 0.73 \\
& {$[2.71]$} & {$[2.62]$} & {$[2.33]$} & {$[2.38]$} \\
on UI since [5, 6] months & $-4.32^{*}$ & $-6.59^{* *}$ & -1.57 & -0.82 \\
& {$[2.46]$} & {$[2.88]$} & {$[2.47]$} & {$[2.57]$} \\
on UI since [6, 7] months & -0.77 & -4.32 & 0.09 & 1.06 \\
& {$[3.19]$} & {$[3.26]$} & {$[2.81]$} & {$[2.93]$} \\
\hline & & & & \\
Adj. $\mathrm{R}^{2}$ & 0.000 & 0.046 & 0.462 & 0.464 \\
Mean Dep. Var & 87.283 & 87.283 & 87.283 & 87.283 \\
N Observations & 28160 & 28160 & 28160 & 28160 \\
N Individuals & 1846 & 1846 & 1846 & 1846 \\
Individual Controls & & $\mathrm{X}$ & & $\mathrm{X}$ \\
Individual FE & & & & $\mathrm{X}$ \\
Time FE & & & & \\
\hline
\end{tabular}

Notes: This table shows estimates of job-search in minutes on time on UI. Included are all job-search responses at time of nonemployment in the examined range of UI duration of individuals with $P \geq 8$. SE (in brackets) are clustered on the individual level. Controls include dummies for gender, German nationality, wave, initial eligibility and UI duration, educational groups and age in years. Time-FE control for calendar months and weekday of survey. *, ${ }^{* *}$ and ${ }^{\star \star *}$ denote significance on $10 \%, 5 \%$ and $1 \%$ significance level, respectively.

Source: Own calculations. CIAB 
Table 4: Search Effort Around UI Exhaustion

\begin{tabular}{lcccc}
\hline & $(1)$ & $(2)$ & $(3)$ & $(4)$ \\
\hline$[-4,-3]$ months since UI exhaustion & -2.86 & $-4.37^{*}$ & $-5.91^{* * *}$ & $-6.53^{* * *}$ \\
{$[-3,-2]$ months since UI exhaustion } & {$[2.21]$} & {$[2.49]$} & {$[2.05]$} & {$[2.07]$} \\
& 0.19 & -1.95 & $-3.21^{*}$ & $-3.76^{* *}$ \\
{$[-2,-1]$ months since UI exhaustion } & {$[2.00]$} & {$[2.17]$} & {$[1.85]$} & {$[1.87]$} \\
& 1.00 & -1.61 & $-3.92^{* *}$ & $-4.24^{* * *}$ \\
{$[-1,0]$ months since UI exhaustion (omitted cat.) } & {$[2.01]$} & {$[1.91]$} & {$[1.59]$} & {$[1.59]$} \\
& 0.00 & 0.00 & 0.00 & 0.00 \\
[0,1] months since UI exhaustion & {$[]$.} & {$[]$.} & {$[]$.} & {$[]$.} \\
& $-2.70^{* *}$ & $-2.68^{* *}$ & $-1.84^{*}$ & -1.74 \\
{$[1,2]$ months since UI exhaustion } & {$[1.30]$} & {$[1.29]$} & {$[1.09]$} & {$[1.09]$} \\
& $-5.11^{* * *}$ & $-4.70^{* * *}$ & -2.41 & -1.88 \\
[2, 3] months since UI exhaustion & {$[1.74]$} & {$[1.70]$} & {$[1.49]$} & {$[1.50]$} \\
& $-9.51^{* * *}$ & $-8.69^{* * *}$ & $-4.76^{* * *}$ & $-4.04^{* *}$ \\
[3, 4] months since UI exhaustion & {$[2.07]$} & {$[1.96]$} & {$[1.70]$} & {$[1.72]$} \\
& $-12.60^{* * *}$ & $-11.36^{* * *}$ & $-6.09^{* * *}$ & $-4.88^{* *}$ \\
\hline Adj. R & {$[2.44]$} & {$[2.26]$} & {$[1.89]$} & {$[1.93]$} \\
\hline Mean Dep. Var & 0.002 & 0.045 & 0.500 & 0.501 \\
N Observations & 84.291 & 84.291 & 84.291 & 84.291 \\
N Individuals & 84601 & 84601 & 84601 & 84601 \\
\hline Individual Controls & 5115 & 5115 & 5115 & 5115 \\
Individual FE & & $X$ & & $X$ \\
Time FE & & & $X$ & $X$ \\
\hline
\end{tabular}

Notes: This table shows estimates of job-search in minutes on time since UI exhaustion. Included are all job-search responses at time of nonemployment in the examined range since UI exhaustion. SE (in brackets) are clustered on the individual level. Controls include dummies for gender, German nationality, wave, initial eligibility and UI duration, educational groups and age in years. Time-FE control for calendar months and weekday of survey. P-Values report the ${ }^{*}{ }^{* \star}$ and ${ }^{* \star \star}$ denote significance on $10 \%$, $5 \%$ and $1 \%$ significance level, respectively.

Source: Own calculations. CIAB 
Table 5: Robustness: Search Effort Around UI Exhaustion

\begin{tabular}{|c|c|c|c|c|c|c|}
\hline & Baseline & $\begin{array}{c}\text { Full } \\
\text { Participants }\end{array}$ & $\begin{array}{l}\text { Constant } \\
\text { Eligibility } \\
\text { over Spell }\end{array}$ & $\begin{array}{c}\text { Re-weighted } \\
\text { to Match } \\
\text { Contact Sample }\end{array}$ & $\begin{array}{c}\text { Non- } \\
\text { Response } \\
\text { as Zero }\end{array}$ & $\begin{array}{l}\text { Controlling for } \\
\text { ALMP, Counseling } \\
\text { and Sanctions }\end{array}$ \\
\hline & (1) & $(2)$ & (3) & (4) & (5) & (6) \\
\hline \multirow[t]{2}{*}[-4,-3]{ months since UI exhaustion } & $-6.53 * * *$ & $-7.10 * * *$ & $-8.26 * * *$ & $-8.04 * * *$ & $-5.79 * * *$ & $-7.18^{* * *}$ \\
\hline & {$[2.07]$} & {$[2.53]$} & {$[2.34]$} & {$[2.02]$} & {$[2.03]$} & [2.11] \\
\hline \multirow[t]{2}{*}[-3,-2]{ months since UI exhaustion } & $-3.76 * *$ & $-4.90^{* *}$ & $-5.43 * * *$ & $-4.84 * * *$ & $-3.20^{*}$ & $-4.35^{* *}$ \\
\hline & {$[1.87]$} & {$[2.27]$} & {$[2.06]$} & {$[1.88]$} & {$[1.84]$} & {$[1.87]$} \\
\hline \multirow[t]{2}{*}[-2,-1]{ months since UI exhaustion } & $-4.24 * * *$ & -3.13 & $-5.41^{* * *}$ & $-5.49 * * *$ & $-4.50^{* * *}$ & $-4.51^{* * *}$ \\
\hline & {$[1.59]$} & {$[1.95]$} & {$[1.76]$} & {$[1.58]$} & {$[1.54]$} & {$[1.57]$} \\
\hline \multirow[t]{2}{*}[-1,0]{ months since UI exhaustion (omitted cat.) } & 0.00 & 0.00 & 0.00 & 0.00 & 0.00 & 0.00 \\
\hline & {$[]$.} & [.] & [.] & {$[]$.} & [.] & [.] \\
\hline \multirow[t]{2}{*}[0,1]{ months since UI exhaustion } & -1.74 & -1.37 & $-2.37^{* *}$ & -1.40 & $-2.27^{* *}$ & $-1.85^{*}$ \\
\hline & {$[1.09]$} & {$[1.35]$} & {$[1.19]$} & {$[1.10]$} & {$[1.07]$} & {$[1.09]$} \\
\hline \multirow[t]{2}{*}[1,2]{ months since Ul exhaustion } & -1.88 & $-3.17^{*}$ & $-3.65^{* *}$ & -1.51 & $-2.89 * *$ & -1.70 \\
\hline & {$[1.50]$} & {$[1.77]$} & {$[1.68]$} & {$[1.50]$} & {$[1.42]$} & {$[1.51]$} \\
\hline \multirow[t]{2}{*}[2,3]{ months since Ul exhaustion } & $-4.04 * *$ & $-4.13^{* *}$ & $-5.59 * * *$ & $-3.77^{* *}$ & $-5.26^{* * *}$ & $-3.60 * *$ \\
\hline & {$[1.72]$} & {$[1.98]$} & {$[1.90]$} & {$[1.69]$} & {$[1.63]$} & {$[1.73]$} \\
\hline \multirow{2}{*}[3,4]{ months since UI exhaustion } & $-4.88^{* *}$ & $-4.91^{* *}$ & $-6.78^{* * *}$ & $-4.16^{* *}$ & $-5.42^{* * *}$ & $-4.35^{* *}$ \\
\hline & [1.93] & {$[2.20]$} & {$[2.14]$} & [1.93] & {$[1.86]$} & {$[1.96]$} \\
\hline Adj. $R^{2}$ & 0.501 & 0.524 & 0.504 & 0.496 & 0.450 & 0.502 \\
\hline Mean Dep. Var & 84.291 & 80.220 & 83.192 & 84.291 & 75.618 & 84.291 \\
\hline N Observations & 84601 & 47505 & 64468 & 84601 & 94304 & 84601 \\
\hline N Individuals & 5115 & 1837 & 3935 & 5115 & 5118 & 5115 \\
\hline Individual FE & $x$ & $x$ & $x$ & $x$ & $x$ & $x$ \\
\hline Time FE & $x$ & $x$ & $x$ & $x$ & $x$ & $x$ \\
\hline Controls for UI Monitoring & & & & & & $x$ \\
\hline
\end{tabular}

Notes: This table shows estimates of job-search in minutes on time on UI. Included are all job-search responses at time of nonemployment in the examined range since UI exhaustion. SE (in brackets) are clustered on the individual level. Time-FE control for calendar months and weekday of survey. Column (1) replicates the results for the baseline sample. Column (2) restricts to individuals who participate the complete duration in the survey while also being nonemployed. Column (3) restricts the baseline sample to individuals with a a constant eligibility during their UI period. Column (4) reweights to match the characteristics of individuals in the contact-sample using dummies for female, non-german nationality, high education and low education. Column (5) treats non-responses, conditional on individuals responding in the future, as zero. Column (6) includes time-varying controls on UI monitoring including information on the time of invitation to a case-worker meeting, the signing of a integration contract with the caseworker, and the receipt of a vacancy referral. ${ }^{*},{ }^{\star \star}$ and ${ }^{\star \star \star}$ denote significance on $10 \%, 5 \%$ and $1 \%$ significance level, respectively.

Source: Own calculations. CIAB 
Table 6: Structural Estimates of Job Search Models

\begin{tabular}{|c|c|c|c|c|c|}
\hline & (1) & (2) & (3) & (4) & (5) \\
\hline & \multirow{2}{*}{$\begin{array}{c}\text { Standard } \\
\text { Model }\end{array}$} & \multicolumn{2}{|c|}{ Reference Dependence } & \multicolumn{2}{|c|}{ Duration Dependence } \\
\hline & & \multicolumn{2}{|c|}{ Model } & Standard & Ref. Dep. \\
\hline & 3 type & 2 type & 3 type & Model & Model \\
\hline \multicolumn{6}{|l|}{ Parameters of Utility Function } \\
\hline \multirow[t]{2}{*}{ Loss aversion $\lambda$} & . & 1.64 & 3.73 & . & 1.17 \\
\hline & & [0.33] & {$[1.01]$} & & {$[0.16]$} \\
\hline \multirow[t]{2}{*}{ Adjustment speed of ref. point $\mathrm{N}$} & . & 149.1 & 349.8 & . & 141.8 \\
\hline & & {$[24.6]$} & [61.8] & & {$[17.1]$} \\
\hline \multirow[t]{2}{*}{ Discount factor (30 days) $\delta$} & 0.995 & 0.995 & 0.995 & 0.995 & 0.995 \\
\hline & {$[0]$} & {$[0]$} & {$[0]$} & {$[0]$} & {$[0]$} \\
\hline \multirow[t]{2}{*}{ Discount factor $\beta$} & 0.100 & 0.475 & 0.916 & 0.494 & 0.461 \\
\hline & [] & {$[0.196]$} & {$[0.0297]$} & {$[0.0175]$} & {$[0.270]$} \\
\hline \multicolumn{6}{|l|}{ Parameters of Search Cost and Productivity } \\
\hline \multirow[t]{2}{*}{ Curvature of search cost $\gamma$} & 12.3 & 4.36 & 0.21 & 1.64 & 0.447 \\
\hline & {$[1.40]$} & {$[1.47]$} & {$[0.065]$} & {$[0.015]$} & {$[0.234]$} \\
\hline \multirow[t]{2}{*}{ Curvature of search effort productivity $\zeta$} & 7.28 & 1.83 & 0.00076 & 0.86 & -0.08 \\
\hline & {$[0.0047]$} & {$[0.68]$} & {$[0.0041]$} & {$[0.040]$} & {$[0.30]$} \\
\hline Composite curvature $\tilde{\gamma}=\frac{\gamma-\zeta}{1+\zeta}$ & 0.60 & 0.89 & 0.21 & 0.42 & 0.56 \\
\hline \multirow[t]{2}{*}{ Share of Highest Cost Type p1 } & 0.44 & 0.49 & 0.34 & 0.38 & 0.39 \\
\hline & {$[0.029]$} & {$[0.021]$} & {$[0.025]$} & {$[0.095]$} & {$[0.037]$} \\
\hline \multirow[t]{2}{*}{ Share of Highest Cost Type p2 } & 0.38 & . & 0.53 & 0.40 & 0,40 \\
\hline & {$[0.051]$} & & {$[0.026]$} & {$[0.027]$} & {$[0,021]$} \\
\hline \multirow[t]{2}{*}{ Time Trend - K } & . & . & . & 0.041 & 0,040 \\
\hline & & & & {$[0.0088]$} & {$[0,017]$} \\
\hline Time trend period cap & . & . & . & 18 & 8 \\
\hline \multicolumn{6}{|l|}{ Model Fit } \\
\hline Number of Moments Used & 49 & 49 & 49 & 49 & 49 \\
\hline Number of Estimated Parameters & 11 & 10 & 13 & 12 & 14 \\
\hline SSE for Hazard & 53.9 & 66.3 & 65.2 & 45.5 & 59.2 \\
\hline SSE for Inital Effort & 28.1 & 12.2 & 22.4 & 22.1 & 3.2 \\
\hline SSE for Effort around Exhaustion & 97.2 & 60.1 & 16.3 & 22.5 & 8.1 \\
\hline Goodness of Fit (SSE) & 179.2 & 138.5 & 103.9 & 90.1 & 70.5 \\
\hline
\end{tabular}

Notes: The table shows parameter estimates for different search models. Parameter estimates for the standard model with 3 types are in column (1) and for the reference-dependent model with 2 and 3 types are in column (2) and (3) respectively. Column (4) and (5) show results with duration dependence in search costs by allowing for an 18 month time trend in $\mathrm{K}$ for the 3 types standard model (column (4)) and the 3 types reference-dependent model (column (5)). Estimation is based on minimum distance estimation. The targeted moments are 1) the withinperson estimates of the evolution of search effort at the beginning of the spell, 2) the evolution of effort at UI exhaustion, and 3) the empirical hazards for the $\mathrm{P}=12$ and $\mathrm{P}=15$ month groups, that are estimated using a regression discontinuity design at the cutoff, to keep the composition between the two groups identical. Appendix table A.27 comprises the full set of parameter estimates. Standard errors for estimated parameters are in brackets.

Source: Own calculations. CIAB 
Additional Figures and Tables are provided in the Online Appendix. 


\section{Imprint}

\section{IAB-Discussion Paper 13|2020EN}

\section{Publication Date}

18 October 2021

\section{Publisher}

Institute for Employment Research

of the Federal Employment Agency

Regensburger Straße 104

90478 Nürnberg

Germany

\section{All rights reserved}

Reproduction and distribution in any form - also in parts - requires the permission of the IAB

\section{Download}

http://doku.iab.de/discussionpapers/2020/dp1320.pdf

All publications in the series "IAB-Discusssion Paper" can be downloaded from

https://www.iab.de/en/publikationen/discussionpaper.aspx

\section{Website}

www.iab.de/en

\section{Corresponding author}

Jörg Heining

Telefon +49-(0)911 179-5392

E-Mail joerg.heining@iab.de 